\title{
Human neutrophils are not activated by Zika virus but reduce the infection of susceptible cells
}

\author{
1 Juliana Bernardi Aggio', Bárbara Nery Porto ${ }^{2}$, Claudia Nunes Duarte dos Santos ${ }^{1}$, Ana Luiza \\ 2 Pamplona Mosimann ${ }^{1 \dagger *}$, Pryscilla Fanini Wowk ${ }^{1 \dagger^{* *}}$ \\ 3 Laboratório de Virologia Molecular, Instituto Carlos Chagas, Fundação Oswaldo Cruz (FIOCRUZ), \\ 4 Curitiba, Brazil \\ $5 \quad 2$ Department of Medical Microbiology and Infectious Diseases, University of Manitoba, Winnipeg, \\ 6 Canada \\ $7 \dagger$ These authors have contributed equally to this work and share senior authorship. \\ 8 * Correspondence: \\ 9 Pryscilla Fanini Wowk, Ana Luiza Pamplona Mosimann \\ 10 pryscilla.wowk@fiocruz.br,ana.mosimann@fiocruz.br
}

11 Keywords: neutrophils, Zika virus, innate immunity, co-culture, NETs, migration.

\section{Abstract}

13 Zika virus (ZIKV) emergence highlighted the need for a deeper understanding on virus-host

14 interaction to pave the development of antiviral therapies. The present work aimed to address the

15 response of neutrophils during ZIKV infection. Neutrophils are an important effector cell in innate

16 immunity involved in the host response to neurotropic arboviruses. Our results indicate that human

17 neutrophils were not permissive to Asian or African ZIKV strains replication. Indeed, after

18 stimulation with ZIKV, neutrophils were not primed against the virus as evaluated by the absence of

19 CD11b modulation, secretion of inflammatory cytokines and granule content, production of reactive

20 oxygen species and neutrophil extracellular traps formation. Overall, neutrophils did not affect ZIKV

21 infectivity. Moreover, ZIKV infection of primary innate immune cells in vitro did not trigger

22 neutrophil migration. However, neutrophil co-cultured with ZIKV susceptible cells (A549) resulted

23 in lower frequencies of infection on A549 cells by cell-to-cell contact. In vivo, neutrophil depletion

24 from immunocompetent mice did not affect ZIKV spreading to the draining lymph nodes. The data

25 suggest human neutrophils do not play a per se antiviral role against ZIKV, but these cells might

26 participate in an infected environment shaping the ZIKV infection in other target cells. 


\section{Introduction}

Zika virus (ZIKV) is an enveloped vector-borne RNA virus, member of the genus Flavivirus which includes important human pathogens. The epidemic potential of flaviviruses is related to the global distribution of their arthropod vectors (mainly Aedes spp.), as well as human population density, mobility and anthropogenic interventions (1). Furthermore, mutation rate in the viral genome and the host immune-status may also impact on viral spread and pathogenesis (2). After decades of sparse reports of infection in Africa and Asia, since 2007 the ZIKV Asian genotype has been implicated in outbreaks in human populations, from Southeast Asia spreading throughout the Americas and reaching Europe (3). In Brazil, ZIKV was first detected in 2015 and recognized as a Public Health Emergency in 2016 (4). More than 220,000 cases were notified and the infection was associated with congenital diseases and to Guillain-Barré Syndrome in adults (5-7).

ZIKV infection has been reported to trigger a rapid recruitment and activation of monocytes, NK cells, plasmacytoid dendritic cells, and lymphocytes, and the upregulation of multiple signaling pathways, like pro-inflammatory cytokines and chemokines in the blood of non-human primates and humans (8-13). Among the innate immune cells, monocytes, dendritic cells and macrophages have been described as targets of ZIKV infection and replication (14-17). It has been suggested that the ensuing innate immune response can be associated with the fate of ZIKV disease. Cell infiltration and inflammation at ZIKV infection sites contributed to placental dysfunctions (18) and encephalitis (19-21). ZIKV affects adhesive properties of monocytes, enhancing their transmigration through endothelial barriers and viral dissemination to neural cells (22). Moreover, neutrophils, Ly6C mid-hi monocytes, and $\mathrm{CD}_{4}{ }^{+}$monocytes from AG129 mice (type I and II IFN receptor deficient), and bone marrow-derived S100A4+ macrophages from AG6 mice (type I, II and III IFN receptor deficient) were shown to be essential for ZIKV dissemination and pathogenesis in peripheral organs and testis (23-25). CD $45^{+} \mathrm{CD} 11 \mathrm{~b}^{+}$monocytes and macrophages play an important role in containing ZIKV spread in the placenta (26), while infected human placental macrophages might gain access to the fetus (27). In this context, the role played by neutrophils during ZIKV infection remains undetermined. Elucidating mechanisms by which neutrophils mediate an antiviral response may 55 damage.

Mature neutrophils are the most abundant granulocytes in the human bloodstream and the major effectors during inflammation and infection. Once in the infection site, neutrophils can rapidly 
eliminate intra- and extracellular pathogens by phagocytosis, oxidative burst, multiple granule

proteolytic enzymes, antimicrobial peptides and neutrophil extracellular traps (NETs) release $(28,29)$.

60 Neutrophils have been also recognized as multitasking cells capable of cross talking with adaptive responses, for example, presenting antigens during viral infections $(30,31)$. The relevance of neutrophils during flaviviruses infection was demonstrated for West Nile virus (WNV) infections, where neutrophils act as Trojan horses carrying the virus into the central nervous system (CNS) enhancing WNV neuroinvasive disease (32). Neutrophil depletion prior to WNV infection resulted in reduced viremia and enhanced host survival (33).

Here, we address the role of neutrophils on ZIKV pathogenesis by the in vitro screening of classical human neutrophil defense mechanisms after stimulation with different ZIKV strains. We report that neutrophils are not targets for ZIKV replication nor good responder to ZIKV, yet neutrophils reduce ZIKV infection when in contact with target cells.

\section{Materials and Methods}

\subsection{Cells}

72 Human peripheral blood was obtained by intravenous puncture from healthy volunteers (both

73 genders, aged between 21-50 years old and with no clinical evidence of disease) upon written

74 consent. The procedures were in accordance with the Conselho Nacional de Ética em Pesquisa-

75 CONEP (CAAE 60643816.6.0000.5248). Human neutrophils were isolated from peripheral blood by negative selection with magnetic microspheres MACSxpress Neutrophil Isolation Kit and MACSxpress Separator (Miltenyi Biotec), according to the manufacturer instructions. Cell viability was determined by Trypan blue exclusion assay and the neutrophil purification was confirmed by cytospin slides (Cytospin 4; Thermo Fisher Scientific) visualized by microscopy (LEICA AF6000 Modular System) (Figure 1A) and flow cytometry.

Peripheral blood mononuclear cells (PBMCs) were isolated using Histopaque density $1.077 \mathrm{~g} / \mathrm{mL}$ (Lonza). CD14 ${ }^{+}$cells were sorted with the MACS system (Miltenyi Biotec), according to the manufacturer instructions and seeded at $5 \times 10^{5}$ cells/mL in RPMI-1640 media with L-glutamine

84 (Lonza) supplemented with 10\% fetal bovine serum (FBS; Gibco), $25 \mu \mathrm{g} / \mathrm{mL}$ gentamicin (Gibco),

$85100 \mathrm{IU} / \mu \mathrm{g} / \mathrm{mL}$ penicillin-streptomycin (Sigma-Aldrich), $12.5 \mathrm{ng} / \mathrm{mL}$ recombinant human GM-CSF

86 (PeproTech), and $25 \mathrm{ng} / \mathrm{mL}$ recombinant human IL-4 (PeproTech). The cells were incubated for 7

87 days at $37^{\circ} \mathrm{C}, 5 \% \mathrm{CO}_{2}$ and humid atmosphere. On the third day of incubation, fresh supplemented 
88

89

90

91

92

93

medium was added to the cell culture. Human monocyte-derived dendritic cells (mdDCs)

differentiation was confirmed by flow cytometry (CD11 $\left.\mathrm{c}^{+/ \text {high }} \mathrm{CD} 14^{+/ \text {low }}\right)$.

Human A549 lung epithelial cells (ATCC CCL-185) were maintained in RPMI-1640 media supplemented with $10 \% \mathrm{FBS}, 25 \mu \mathrm{g} / \mathrm{mL}$ gentamicin, and $100 \mathrm{IU} / \mu \mathrm{g} / \mathrm{mL}$ penicillin-streptomycin at $37^{\circ} \mathrm{C}, 5 \% \mathrm{CO}_{2}$ and humid atmosphere. Aedes albopictus mosquito C6/36 cells (ATCC CLR-1660) were grown in Leibovitz's media (L-15; Gibco) supplemented with 5\% FBS, $25 \mu \mathrm{g} / \mathrm{mL}$ gentamicin, and $0.26 \%$ tryptose (Sigma-Aldrich) at $28^{\circ} \mathrm{C}$.

\subsection{Zika virus}

Viral stocks of the ZIKV Asian strains, the clinical isolate BR 2015/15261 (34) and PE243 (35), and the ZIKV ancestral African isolate MR766 (36) were prepared in C6/36 cells. Seven days postinfection cell culture supernatant was collected, clarified by centrifugation and later titrated by fociforming immunodetection assay in C6/36 cells (37). In parallel, C6/36 cells were maintained in the same conditions without viral addition. This conditioned supernatant, hereby called mock, was used as a negative control for cell activation and infection.

\subsection{Cell interaction with ZIKV}

Neutrophils at $2.5 \times 10^{5}$ cells $/ 200 \mu \mathrm{L}$ of RPMI-1640 media supplemented with $25 \mu \mathrm{g} / \mathrm{mL}$ gentamicin and $100 \mathrm{IU} / \mu \mathrm{g} / \mathrm{mL}$ penicillin-streptomycin were incubated for 2 hours with ZIKV strains (BR 2015/15261, PE243 and MR766) using a multiplicity of infection (MOI) of 1 at $37^{\circ} \mathrm{C}, 5 \% \mathrm{CO}_{2}$ and humid atmosphere under agitation. As a control for cell activation, neutrophils were also incubated in the same conditions with mock, $100 \mathrm{ng} / \mathrm{mL}$ of Escherichia coli lipopolysaccharide (LPS-EK, InvivoGen), or $16 \mathrm{nM}$ of phorbol 12-myristate 13-acetate (PMA; Sigma-Aldrich). After the $2 \mathrm{~h}$ incubation period, neutrophils were washed twice (250 x $g ; 10$ minutes) in non-supplemented media and seeded in 96-well plates in RPMI-1640 media supplemented with 10\% FBS and antibiotics at $37^{\circ} \mathrm{C}, 5 \% \mathrm{CO}_{2}$ and humid atmosphere. Supernatant collected right after the wash step was called input and used as a control to account for any remaining viruses in the neutrophil culture after washing out the initial inoculum (Figure 1B). Two (input), 6, 12 and 24 hours after the beginning of the stimulation, neutrophils and the culture supernatant were harvested and analysed. Supernatants were stored at $-80^{\circ} \mathrm{C}$ until further analysis. In some experiments, to exclude non-internalized virus binding in their surface, neutrophils were treated right after the wash steps ( 2 hours/input) with 
$1170.05 \%$ trypsin-EDTA (Gibco) (Figure 1B) for 10 minutes at room temperature, followed by FBS

118 addition, washed and suspended in the new media (38).

119 Chemokines in PBMCs and mdDCs culture supernatant were quantified 24 and 48 hours after ZIKV

120 stimulation. For that, PBMCs (after isolation) and mdDCs (after 24 hours of resting) at $1 \times 10^{6}$

121 cells $/ 500 \mu \mathrm{L}$ were stimulated with the same protocol described above for neutrophils (Figure 1B), but

122 seeded in 24-well plates.

123 A549 and C6/36 cells were incubated for 2 hours with ZIKV strains (1 MOI) (or different stimuli

124 when indicated) in $400 \mu \mathrm{L}$ of media without FBS. After the incubation period, cells were washed

125 twice with non-supplemented media and kept in media supplemented with $10 \%$ FBS and antibiotics

126 during the indicated times.

\subsection{Flow cytometry}

128 Neutrophils and A549 cells viability were determined at the indicated time points using Annexin V

129 (ImmunoTools) and 7-Amino-Actinomycin (7-AAD; BD Bioscience) following manufacturer's

130 instructions (PE Annexin V Apoptosis Detection Kit; BD Bioscience). The frequency of ZIKV

131 antigen in neutrophils, A549 cells and C6/36 cells was measured by staining with a flavivirus group

132 specific envelope protein (E) monoclonal antibody 4G2 (ATCC HB-112) (37). Briefly, the cells were

133 recovery, and if necessary were detached from the cell culture flask (A549 cells with trypsin and

$134 \mathrm{C} 6 / 36$ with cell scraper), and blocked (5\% FBS and 1\% human AB serum in PBS) for 20 minutes at

135 room temperature. Next, cells were fixed and permeabilized using the Cytofix/Cytoperm

136 Fixation/Permeabilization Kit (BD Biosciences), stained with 4G2 FITC-conjugated antibody for 45

137 minutes at $37^{\circ} \mathrm{C}$, and washed twice. Alternatively, these cells were labeled with $4 \mathrm{G} 2$ antibody, goat

138 anti-mouse Alexa Fluor 488 secondary antibody (Thermo Fisher Scientific) and Vybrant

139 DyeCycleViolet Stain (Thermo Fisher Scientific), and fixed in slides pre-treated with poly-L-lysine

140 (Sigma-Aldrich) for confocal microscopy imaging (LEICA SP5 AOBS). For surface markers

141 staining, neutrophils were blocked and incubated with fluorochrome-conjugated mouse anti-human

142 monoclonal antibodies specific for CD11b (clone ICRF44), CD16 (clone 3G8), CD62L (clone

143 DREG-56) (BD Biosciences), and Hu Axl (clone D57HAXL) (eBioscience), for 20 minutes at room

144 temperature. To measure intracellular reactive oxygen species generation, neutrophils were labeled

145 with $0.5 \mu \mathrm{M}$ of 5-(and-6)-chloromethyl-2',7'-dichlorodihydrofluorescein diacetate, acetyl ester (CM-

$146 \mathrm{H}_{2} \mathrm{DCFDA}$ ) probe (Invitrogen) for 45 minutes at $37^{\circ} \mathrm{C}$. Cytokines and chemokines in the supernatant 
147 of neutrophils, PBMCs and mdDCs culture supernatants were quantified by the Cytometric Bead

148 Array (CBA) method using the Human Inflammatory Cytokines Kit and Human Chemokine Kit (BD

149 Biosciences), following manufacturer's instructions. Flow cytometry was performed on a FACS

150 Canto II with BD FACSDiva software (BD Biosciences) and the acquired data analyzed on

151 FlowJoV10 (BD Biosciences).

\section{$152 \quad 2.5 \quad$ RT-qPCR}

153 Neutrophils RNA was extracted using the RNeasy Mini Kit (Qiagen) according to the manufacturer's 154 instructions. RT-qPCR to detect ZIKV was performed in a $20 \mu \mathrm{L}$ reaction final volume containing

155 GoTaq one-step RT-qPCR master mix (Promega), 25 ng of sample RNA, $500 \mathrm{nM}$ of the ZIKV1086

156 and ZIKV1162c oligonucleotides, and $200 \mathrm{nM}$ of ZIKV1107-FAM probe according to a previously

157 described protocol (39). RNase P (RPPH1) was used as a reference gene (40). All reactions were

158 carried out in a LightCycler 96 System and the fluorescence threshold limit of the probe was

159 automatically set by LightCycler software (Roche). The results were represented as the $\Delta C t$ between

160 ZIKV and RNAase P amplification.

\section{$161 \quad 2.6 \quad$ Neutrophil elastase measurement}

162 Elastase was measured using the Human PMN-Elastase ELISA Kit (Invitrogen) in neutrophil culture

163 supernatant at 6 hours after stimulation. Cell culture supernatant $(100 \mu \mathrm{L})$ was added to a microwell

164 plate coated with anti-human polymorphonuclear (PMN) elastase polyclonal antibody and incubated

165 at room temperature for 1 hour with a Horseradish peroxidase-conjugated anti- $\alpha$ 1-proteinase

166 inhibitor antibody. The immune complex was detected by adding tetramethyl-benzidine substrate

167 solution and the absorbance was determined at $450 \mathrm{~nm}$ on a microplate reader (BioTek Synergy H1

168 Hybrid).

\subsection{Neutrophil extracellular traps assessment}

170 Neutrophils at $2 \times 10^{5}$ cells/200 $\mu$ L of RPMI-1640 media supplemented with antibiotics were

171 incubated for 5 hours with either mock, ZIKV strains (1 MOI), or 160 nM of PMA in Lab-Tek

172 chamber slides (Thermo Fisher Scientific) pre-treated with poly-L-Lysine at $37^{\circ} \mathrm{C}, 5 \% \mathrm{CO}_{2}$ and

173 humid atmosphere. For NETs visualization, the supernatant was carefully removed and the cells were

174 fixed with 3\% paraformaldehyde (Sigma-Aldrich), and stained with an anti-acetyl-histone H3

175 polyclonal antibody (Sigma) followed by a mouse anti-rabbit Alexa Fluor 488 secondary antibody 
176 (Sigma) and Vybrant DyeCycleViolet Stain (Thermo Fisher Scientific) for 45 minutes at $37^{\circ} \mathrm{C}$. The

177 slides were sealed with n-propyl gallate (Sigma-Aldrich) and observed by confocal microscopy

178 (LEICA SP5 AOBS). For NETs quantification, following the stimulation period, neutrophils were

179 treated with $0.04 \mathrm{U} / \mu \mathrm{L}$ of Turbo DNAse (Thermo Fisher Scientific) for 10 minutes at $37^{\circ} \mathrm{C}$. The

180 enzymatic digestion was stopped with 5 mM EDTA (41). The culture was centrifuged (300 x $\mathrm{g}$ for 1

181 minute), the supernatant collected and 5-fold diluted. Free double-stranded DNA (dsDNA) was

182 quantified using Quant-IT PicoGreen dsDNA kit (Invitrogen) in a Qubit 2.0 fluorometer (Invitrogen)

183 according to the manufacturer's recommendations. To evaluate the effect of pre-formed PMA-

184 induced NETs on viral particles capture, neutrophils were stimulated during 5 hours with media or

185 PMA in the same conditions described above. Then, the culture was stimulated for 1 hour with ZIKV

186 strains (1 MOI). Next, neutrophils were centrifuged (300 x g for 1 minute) and the supernatant (with

187 virus not attached to the traps) collected and quantified by foci-forming immunodetection assay in

188 C6/36 cells.

\subsection{Neutrophil chemotaxis assay}

190 Neutrophils at $3 \times 10^{5}$ cells/200 $\mu$ L of RPMI-1640 media supplemented with antibiotics were seeded

191 on a $3 \mu \mathrm{m}$ pore Thin Cert insert (Greiner Bio-One) coupled to a 24-well plate. Inducers of neutrophil

192 chemotaxis were added to the bottom well in $600 \mu \mathrm{L}$ of RPMI-1640 media containing 1,000 or

19350,000 pg of recombinant human (rh-) IL-8 (PeproTech) or A549 cells culture previously infected for

19448 hours with mock or ZIKV PE243 (1 MOI). For this specific experiment, infected A549 cells were

195 maintained in the absence of FBS. RPMI-1640 media and A549 cells stimulated with mock were

196 used as a negative control for cell migration. After 2 hours at $37^{\circ} \mathrm{C}, 5 \% \mathrm{CO}_{2}$ and humid atmosphere,

197 migratory neutrophils were collected from the bottom well system and the cell concentration

198 determined by Turk dye counting. The chemotactic index was calculated as the ratio of the number of migratory neutrophils in each condition divided by the number of neutrophils that migrated in the negative control (42).

\subsection{Co-culture assay}

202 A549 cells (seeded in 24-well plates) at $1 \times 10^{5}$ cells/ $400 \mu \mathrm{L}$ in RPMI-1640 media supplemented with 203 antibiotics were stimulated for 2 hours with mock or ZIKV strains (1 MOI) in the absence or 204 presence of neutrophils of a ratio of 1:5. Afterwards, neutrophils were assessed for surface markers 205 by flow cytometry as described above, and A549 cells were washed twice and kept in $500 \mu \mathrm{L}$ of 
RPMI-1640 media supplemented with 10\% FBS and antibiotics for 16 hours. At the end of the 18 hours of infection, A549 cells were assessed for viability and intracellular ZIKV antigen by flow cytometry. To evaluate if neutrophils were physically interacting with A549 cells through surface proteins, in some experiments, before adding A549 cells cells culture, neutrophils were treated with trypsin for 10 minutes at room temperature, added FBS, washed and suspended in fresh media. In a different co-culture experiment setting, A549 cells were incubated for 2 hours with mock or ZIKV strains (1 MOI), washed twice and incubated for 24 hours. Then, neutrophils in a ratio of 1:5 were

213 added or not to these cultures for 16 hours. At the end of the 40 hours of infection, A549 cells were

214 evaluated for frequency of ZIKV antigen.

\section{$215 \quad 2.10$ In vivo ZIKV infection model}

216 C57BL/6 mice were obtained from Instituto Carlos Chagas/FIOCRUZ-PR animal facility, and

217 maintained and handled according to the directives of the Guide for the Care and Use of Laboratory

218 Animals of the Brazilian National Council of Animal Experimentation. The protocols were approved

219 by the Committee on the Ethics of Animal Experimentation from Fundação Oswaldo Cruz -

220 CEUA/FIOCRUZ (license LW 03-19). Both male and female mice between 8-12-week-old were

221 infected subcutaneously in the hind footpad with ZIKV PE243 (5x10 FFU, $10 \mu \mathrm{L})$ to determine

222 systemic ZIKV titers. After 10 minutes, 1, 3, 6 and 24 hours of infection, spleen, kidney and lymph

223 nodes (popliteal (pLN), lumbar aortic (laLN), and sciatic lymph nodes (sLN)) were aseptically

224 removed, homogenized using a tissue grinder, submitted to three freeze-thaw cycles and the viral

225 load measured by foci-forming immunodetection assay in C6/36 cells. Both ipsi- and contralateral

226 lymph nodes per animal were pooled together. Blood was collected through cardiac puncture at the

227 same time points and plasma viremia was titrated in C6/36 cells.

To evaluate the neutrophil influence in ZIKV spread to peripheral organs, neutrophils were depleted and the animals infected with ZIKV. Animals were inoculated intraperitoneally with $200 \mu \mathrm{L}$ of PBS containing $400 \mu \mathrm{g}$ of anti-mouse Ly6G (clone 1A8; BioxCell) or mouse IgG2a isotype control (clone C1.18.4; BioxCell). Control animals received $200 \mu \mathrm{L}$ of PBS (Lonza). After 18 hours, the frequency of neutrophils in total blood was evaluated through flow cytometry by surface staining with

233 fluorochrome-conjugated anti-mouse monoclonal antibodies specific for CD11b (clone M1/70), and

234 Ly6C/G (clone RB6-8C5) (BD Biosciences). Neutrophil-depleted animals were inoculated in the 235 hind footpad with PBS only or 1,000 ng of LPS (to induce an inflammatory environment). After 3 236 hours, mice were inoculated with $10 \mu \mathrm{L}$ of ZIKV PE243 (1.3x10 6 FFU) in the same footpad. One 
237 hour later, popliteal lymph nodes (pLNs) were pooled, harvested and the viral title determined as

238 above.

\section{$239 \quad 2.11$ Statistical Analyses}

240 Analyses were performed using GraphPad Prism 8 (GraphPad Software, Inc.). Wilcoxon matched-

241 pairs signed rank test (nonparametric paired t-test) was used in the analysis of the in vitro

242 experiments with primary human cells to clarify individual patterns. One-way Anova with Tukey's

243 multiple comparison test was used in animal experiments to compare the average of groups. A cut-off

244 of $\mathrm{p}<0.05$ was considered significant.

\section{Results}

\subsection{ZIKV does not establish a productive infection in human neutrophils}

247 We first evaluate whether any of the tested ZIKV strains trigger human neutrophil death until 24

248 hours after stimulation (Figure 1B). It was observed a similar exposition of phosphatidylserine

249 between mock- and the ZIKV strains-stimulated neutrophils over time and low loss of cellular

250 integrity indicated by 7-AAD uptake (Supplementary Figure 1). The observed neutrophil phenotype

251 concurs with previous knowledge that in the absence of inflammation, neutrophils have a short life

252 span and undergo constitutive apoptosis (43), and LPS, that is a positive control of neutrophil

253 activation, restricted apoptosis at the late time points (44).

254 Viruses, in addition to subverting the target cell into a reservoir for replication and dissemination,

255 may use the infected cells as a Trojan horse to overcome physiological host defense barriers (32).

256 The infection can also result in the inhibition of important cell signal transduction pathways (17). To

257 address this issue, we sought to understand whether human neutrophils are susceptible to and sustain

258 ZIKV infection. No positive cells for the intracellular staining of the ZIKV E protein (4G2 antibody)

259 were detected 24 hours after stimulation with the three ZIKV strains tested through

260 immunofluorescence or flow cytometry (Figure 1C and 1D). It contrasts with the infection observed

261 in the highly permissive mosquito cell line C6/36 (Figure 1C and 1D). The possibility of an active

262 internalization of a few viral particles by neutrophils via receptors or phagocytosis could not be

263 excluded, even though we reported the absence of AXL in the surface of human neutrophils, which

264 was expressed in the ZIKV susceptible human lineage A549 (Figure 1E). Indeed, ZIKV RNA could

265 be detected in neutrophils incubated with the viruses (Figure 1F). However, we did not observe a 
significant increase in ZIKV RNA levels over time (Figure 1F) nor the release of functional viral particles in loads greater than the input (Figure 1G). Treatment of neutrophils with trypsin after the wash steps resulted in the reduction but not in the abolishment of virus RNA levels (Figure 1H). This suggests that the low RNA levels measured cannot be fully attributed to viral inoculum leftover, and at least partially, could be explained by the virus particles that stick at the cell membrane.

\subsection{Human neutrophils are mild responsive to direct contact with ZIKV}

272 The recognition of viral elements in the cell cytosol triggers defense mechanisms involved in viral

273 replication control and inflammation. However, a significant part of neutrophil activation

274 mechanisms is coordinated through the signaling of cell surface receptors (43). Following the

275 experimental setting in Figure 1B, the expression of the adhesion integrin CD11b was upregulated

276 over time following LPS stimulation, while the selectin adhesion receptor CD62L was

277 downregulated (Figure 2A-C), indicating priming of neutrophils $(45,46)$. Nevertheless, no differences

278 were observed in the expression of CD11b molecule between mock- and the ZIKV strains-stimulated

279 neutrophils (Figure 2B), and only slight differences were observed in the expression of CD62L

280 (Figure 2C). No significant differences were observed in the IL-8/CXCL8 levels secreted by

281 neutrophils after 24 hours of stimulation between mock and ZIKV (Figure 2D). Similar results were

282 obtained for IL-1 $\beta$, IL-6 and IL-10 (data not shown). The low levels of elastase detected in

283 neutrophils culture supernatant after 6 hours of stimulation with ZIKV BR 2015/15261 were similar

284 to mock-stimulated cells (Figure 2E). It was also noted an overall low production of ROS in

285 neutrophils after ZIKV stimulation, measured by the oxidation of chloromethyl- $\mathrm{H}_{2} \mathrm{DCFDA}_{\text {(Figure }}$

$2862 \mathrm{~A}$ and $2 \mathrm{~F}$ ), in contrast to the oxidative stress generated by PMA stimulation, a well-known ROS

287 inducer. We confirmed that NETs were not induced by any ZIKV strains tested after 5 hours of

288 stimulation through the absence of web-link extracellular structures colocalizing with DNA and

289 histone (Figure 3A) and the absence of free DNA in neutrophil supernatants (Figure 3B). PMA is a

290 robust NET inducer over a 3-4 hour time course via ROS (47), as observed here (Figure 3A-B).

291 Moreover, ZIKV was not trapped by NETs, as the same loads of ZIKV were quantified in the

292 supernatant of neutrophils stimulated or not with PMA (Figure 3C). To confirm that neutrophil does

293 not impact ZIKV particles, neutrophils were stimulated for 6 hours with ZIKV, and the free virus

294 recovered from the supernatant did not have impaired infectivity in a subsequent infection of

295 susceptible cells (Figure 4). 


\subsection{ZIKV infection does not provide a favorable environment for human neutrophil} migration

298

Although neutrophils are circulatory cells and therefore have the potential to encounter viruses in the bloodstream, their fate is to contribute to the inflammation on the infected tissue. In fact, the priming of neutrophils in the circulation by an isolated stimulus is insufficient, and their complete activation to full capacity is a multistep process achieved after their transmigration through the endothelium following a chemotactic gradient (43). Secretion of IL-8/CXCL8, an important human neutrophil chemoattractant, was measured after ZIKV stimulation of mdDCs and PBMCs for 24 and 48 hours. LPS was used as a positive control of activation and boosted the chemokines production (Figure 5A). A concentration of recombinant human IL-8 (rhIL-8) corresponding approximately to the ones detected in the mdDCs and PBMCs supernatant (1,000 pg) was not enough to induce neutrophil migration in a transwell assay (Figure 5B). Neutrophils migrated with a 50-fold higher rhIL-8 concentration (Figure 5B). Interestingly, a more permissive cell line, A549 cells, when infected with ZIKV PE243 for 48 hours, also did not promote neutrophil migration (Figure 5B).

\subsection{Human neutrophils reduce ZIKV infection in A549 by cell-cell contact}

To mimic a situation where neutrophils reached an infected environment after migration, we cocultured neutrophils with A549 cells. Neutrophils were added to A549 cells concomitant with ZIKV infection. Both stimuli were maintained for 2 hours and then removed. The A549 cells infection frequency was evaluated 16 hours after the removal of the viral input by the detection of ZIKV E protein (4G2) (Figure 6A). A significant reduction in A549 cell infection was observed when neutrophils were added during the infection time (Figure 6A and 6B). We did not detect a reduction in the frequency of A549 cells annexin $\mathrm{V}^{-7} 7-\mathrm{AAD}^{-}$due to neutrophil presence (Figure 6C). We previously hypothesized that a small number of particles might have been internalized by neutrophils and a reduced fraction of the virus particles could be binding to the neutrophils surface. Nevertheless, such a small reduction in the number of free viral particles is not enough to explain the decrease in the infection rate observed in the co-culture. Besides, no decrease in A549 infection was detected when ZIKV was pre-incubated with neutrophils (Figure 4). Neutrophils co-cultured with A549 cells did not modulate CD11b and CD62L receptors (Figure 6D and 6E), indicating the reduction of the infection is not due to neutrophils activation. However, neutrophil treatment with trypsin before addition to A549 cells restored A549 cells infection frequencies and replication (Figure 6A, 6F and $6 \mathrm{G})$. Therefore, we hypothesized that neutrophils were interacting with A459 cells through surface 
protein membrane components and impairing ZIKV infection. The treatment with trypsin did not

328 significantly affect the viability of neutrophils (annexin $\mathrm{V}^{-7}$-AAD ${ }^{-}$) (Figure 7A), nor the expression of CD11b (Figure 7B and C), but significantly reduce the expression of CD62L on neutrophils

330 (Figure 7B and 7D), suggesting an impact on neutrophil surface proteins by trypsin. In an alternative 331 co-culture setting, aimed to mimic the neutrophil role to an established ZIKV infection, A549 cells

332 were infected for 24 hours with ZIKV strains and after this time neutrophils were added to the culture

333 for 16 hours. Even in a scenario where infection was already established, a significant reduction in

334 the frequency of ZIKV infection was observed after neutrophils addition (Supplementary Figure 2).

\section{$335 \quad 3.5 \quad$ Neutrophil depletion does not alter ZIKV titers in the draining lymph node}

336 After subcutaneous infection in the hind footpad, ZIKV PE243 were detected only up to 3 hours after 337 infection in the lymph nodes (popliteal (pLN), lumbar aortic (laLN), and sciatic lymph nodes (sLN))

338 of C57BL/6 immunocompetent mice (Figure 8A). ZIKV PE243 were not detected in the spleen,

339 kidney or blood of these animals in any of the assessed times. Therefore, we used the pLN 1 hour of

340 ZIKV infection as a viral spread indicator site in our subsequent studies. C57BL/6 mice had

341 neutrophils significantly reduced through pre-treatment with a monoclonal antibody targeting Ly6G

342 (Figure 8B and 8C). Eighteen hours post-neutrophil depletion treatment and 3 hours prior to ZIKV

343 PE243 subcutaneous infection, mice were inoculated subcutaneously in the hind footpad with LPS to

344 stimulate cell migration to the injection site (Figure 8D). The animals treated with the anti-Ly6G

345 antibody (Ly6G x LPS) presented similar titers of ZIKV in the pLN than animals that received no

346 antibody treatment (PBS x LPS) (Figure 8D). The slightly reduced titers in the pLN seen in mice that

347 received LPS in comparison with the ones that received PBS in the footpad were attributed to the

348 inflammatory context. This result suggests that, in this model, the presence of neutrophils was not

349 essential to contain ZIKV spread to the draining lymph node.

\section{Discussion}

351 Neutrophil-inflammatory responses triggered by viral infection are necessary for an effective

352 antiviral immunity (48-51), but can also become dysregulated and result in tissue injury $(52,53)$. This

353 concept could be extended to ZIKV pathology, in which neutrophils could be associated with the

354 virus neurotropic nature, the ability to cause injury to the reproductive tract and be sexually

355 transmitted, as well as the long-term viral persistence in some body fluids and tissues (3). In order to 
investigate these possibilities, we interrogated the response of human neutrophils to Asian and African ZIKV strains in a diverse experimental setting.

358 Neutrophils were suggested to be permissive to ZIKV as viral RNA was found in myeloperoxidase ${ }^{+}$ 359 neutrophils present in the lymph nodes of cynomolgus macaques 7 days post-infection (10), and in $360 \mathrm{CD} 45^{+} \mathrm{CD} 11 \mathrm{~b}^{+}$neutrophil-myeloid cells in the placenta of AIR mice (vertical transmission model in a Rag1-deficient mouse) (26). In contrast to those previous findings, our results shown that, beside some ZIKV RNA detection, human neutrophils do not appear to support any significant ZIKV replication and do not represent a remarkable ZIKV reservoir. This is in agreement with previous reports demonstrating that ZIKV preferentially targets $\mathrm{CD}_{14}{ }^{+} \mathrm{CD} 16^{+}$monocytes in the blood (16). Also according to our data, AXL, a TAM family tyrosine kinase that has been described as a facilitator of ZIKV infection due to attenuation of type I IFN (54), was found to be absent from neutrophils surface. Nevertheless, ZIKV receptors and co-receptors are still not well characterized and AXL is one of the cell surface molecules that could help mediate ZIKV infection.

Surprisingly, stimulation of neutrophil with ZIKV did not promote a strong cell activation or any of the classical neutrophil microbicidal mechanisms as noted by the absence of CD11b modulation, secretion of inflammatory cytokines and elastase, production of reactive oxygen species and NETs. These results indicate neutrophils that presented a non-responsive phenotype in our experimental settings and would not be the major source of inflammatory mediators during ZIKV infection. Other viruses, such as Human immunodeficiency virus-1, induced activation on neutrophils by modulating the expression of several Toll-like receptors, CD11b and CD62, promoting the secretion of IL-6 and TNF- $\alpha$, and altering ROS production (55). According to our results, ZIKV and Dengue virus type 2 were previously shown not be able to provoke NETs induction in mice (56). Interestingly, our data pointed out that ZIKV particles are not captured by NETs in a context of the DNA web induced by a secondary stimulus. Zanluqui et al. preprint manuscript (57), also addresses the role played by neutrophils during ZIKV infection. Corroborating our finds, the authors shown the lack of ZIKV interference in human neutrophil viability and NETs release, as well as mice neutrophils did not

382 display a pro-inflammatory profile and ROS production against the virus (57). A viral escape from

383 innate immune components could result in delayed immune responses favoring virus spread.

384 Furthermore, we cannot rule out a possible suppression of neutrophil action by ZIKV, as already 
activation impaired during ZIKV replication $(14,16,17,58,59)$. Moreover, a cohort of rhesus monkeys produced minimal systemic cytokine response to ZIKV infection (9).

Furthermore, several reports have indicated that neutrophils migrate to different tissues during ZIKV infection in IFN receptor-deficient mouse, such CNS, spleen, spinal cord, epididymis, and testis $(19,20,24,60,61)$, and in humans and non-human primates mucosa, placenta, and fetus $(11,62,63)$. Patients during acute or recovery disease phase, THP-1 cells and monocytes secrete increased amounts IL-8/CXCL8 following ZIKV infection (12,13,16,64). Moreover, myeloid cells in AG129 mice challenged with ZIKV were responsible for the production of cytokines involved in leukocyte recruitment and viral dissemination to peripheral organs (23). Despite these reports, in our settings, 48 hours of ZIKV infection of mdDCs and PBMCs did not induce sufficient levels of IL-8 to promote neutrophil migration in vitro. Even in ZIKV infected A549 cells, that endure high levels of viral replication and can generate a more complex environment, the neutrophil migration is not promoted. Frumence et al. (65) shown the secretion of soluble IL-8 in ZIKV infected A549 cells, however at low levels, confirming that the in vitro assay we used presents limitations in order to promote neutrophil migration.

In an attempt to assess the putative impact of neutrophil migration to infected tissues in vitro, we used a co-culture system with A549 cells. Our results show a reduction in the rate of ZIKV infection of A549 cells when neutrophils are present at the moment of the infection or in a pre-established infection. This infection impairment seems not to be related to neutrophil activation, but due to a physical interaction between surface molecules in both cells. It has been shown that cell-to-cell contact between neutrophils and A549 cells leads to a pro-proliferative effect on these cells involving the release of elastase and COX-2 products by neutrophils (66). An increase in the production of IL-6 and IL-8 by A549 cells (67), and induction of A549 cell death by apoptotic neutrophils by soluble

409 Fas ligand (68) have also been reported. However, it was not the case in our model, where neutrophil

410 presence did not affect A549 cell viability. The loss of CD62L in neutrophils after treatment with 411 trypsin, a condition in which the frequency of ZIKV infection were restored in A549 cells, might 412 bear a connection to the pathways involved in the neutrophil modulation of ZIKV infection in A549 413 cells. Herbert et al. (69) have reported that the $\beta 2$ - integrin ligand LFA-1 on neutrophils binds to the 414 ICAM-1 receptor on epithelial cells and mediate, at least in part, epithelial damage, neutrophil 415 degranulation and reduction of Respiratory syncytial virus (RSV) load. It remains to be defined what 416 molecules and pathways might be involved during these cell-cell interactions that potentially 
417 contribute to the reduction of viral infection and proliferation and that could be explored in the future 418 as targets against flavivirus infection. Secondary action of neutrophils in the site of infection is linked 419 to the mosquito saliva components. During Semliki Forest virus infection, the mosquito bite induced 420 a neutrophil influx at the site of the bite, and these cells helped coordinate the entry of susceptible 421 myeloid cells that are permissive to viral infection (70).

422 Finally, in order to gain a better understanding on the role played by neutrophils in ZIKV clearance at 423 the inflammation site, we depleted neutrophils from C57BL/6 mice. In this scenario, we did not 424 observe a direct action of neutrophils in preventing ZIKV spread to the lymph nodes in the first hour 425 after ZIKV inoculation in a setting where an inflammatory environment had been previously induced 426 by LPS injection. Interestingly, other authors reported that besides an extensive neutrophil 427 recruitment to the inflammation site after certain virus infections (RSV, Herpes simplex virus type 1 428 and Coxsackievirus B3), neutrophils did not play an important role in viral replication and disease 429 susceptibility, which in turn was exerted by monocytes and macrophages (71-74).

430 Immunocompetent mice, like C57BL/6 strain, readily resolve ZIKV infection and might be a limited 431 model to answer long-term questions. However, IFN pathway deficient models, despite being 432 valuable tools to study ZIKV pathology, could bear differences in the kinetics of neutrophil 433 recruitment. Intracranial ZIKV infection in C57BL/6 WT or Rag1 $1^{-/-}$mice (deficient in mature $\mathrm{T}$ and 434 B cells) resulted in a lethal encephalitis with infiltration of macrophages and NK cells (19). Neonatal 435 immunocompetent mice challenged subcutaneously with ZIKV elicit CD8 ${ }^{+}$T cells to the CNS (20).

436 In contrast, IFNAR ${ }^{-/-}$mice (IFN type I and II receptor deficient) infected by both routes, shown an 437 accelerated ZIKV spread to peripheral organs and to the CNS, where it elicits an inflammatory 438 response characterized by neutrophils infiltration $(19,20)$. In the context of infection with the 439 pulmonary bacteria Francisella tularensis and Influenza virus, the absence of IFN-I results in higher 440 neutrophil recruitment $(75,76)$. It would be of considerable interest to assess the production of 441 neutrophil chemoattractants following ZIKV infection in the CNS of humans pos mortem, since 442 ZIKV antagonizes human IFN-I (77).

443 In conclusion, the results indicate that human neutrophils are slightly activated by direct contact with 444 ZIKV. However, the direct interaction between ZIKV and neutrophils does not contribute to the viral 445 replication or to the inflammatory disease associated with the virus infection. Conversely, human 446 neutrophils are able to reduce ZIKV infection and replication on A549 cells. It is not yet clear 447 though, what is the mechanistically role of neutrophils in this context. Finally, despite not being a 
448 target cell for ZIKV infection, our data suggest that, in vitro, neutrophils play a role in shaping ZIKV

449 infection in other target cells.

450 Conflict of Interest

451 The authors have no financial conflicts of interest.

\section{Author Contributions}

453 JBA and PFW conceptualized, designed, and performed the experiments and data analysis. BNP and

454 ALMP contributed to the interpretation and discussion of the data. CNDS contributed with her 455 expertise in virology. All authors prepared the manuscript.

\section{Funding}

457 This research was funded by the Conselho Nacional de Desenvolvimento Científico e Tecnológico 458 (CNPq-Universal - 444857/2014-1) and by Instituto Carlos Chagas/Fiocruz-PR (CNPq - PROEP459 ICC 442356/2019-6). CNDS (307176/2018-5) is a CNPq fellow.

\section{Acknowledgments}

461 We thank Instituto Carlos Chagas's staff and colleagues at the Molecular Virology Laboratory for 462 technical assistance, and Juliano Bordignon for critical reading. We also thank the Program for 463 Technological Development in Tools for Health - PDTIS/FIOCRUZ for the use of the Flow

464 Cytometry (RPT08L), Microscopy (RPT07C), and Animal facilities at Instituto Carlos

465 Chagas/Fiocruz-PR.

\section{References}

467 1. Olson MF, Juarez JG, Kraemer MUG, Messina JP, Hamer GL. Global patterns of aegyptism 468 without arbovirus. PLoS Negl Trop Dis (2020) 15:e0009397. doi:10.1101/2020.07.20.212209

469 2. Pierson TC, Diamond MS. The continued threat of emerging flaviviruses. Nat Microbiol 470 (2020) 5:796-812. doi:10.1038/s41564-020-0714-0

471 3. Pierson TC, Diamond MS. The emergence of Zika virus and its new clinical syndromes.

$472 \quad$ Nature (2018) 560:573-581. doi:10.1038/s41586-018-0446-y

473 4. Zanluca C, de Melo VCA, Mosimann ALP, dos Santos GIV, dos Santos CND, Luz K. First report of autochthonous transmission of Zika virus in Brazil. Mem Inst Oswaldo Cruz (2015) 110:569-572. doi:10.1590/0074-02760150192 
5. Cugola FR, Fernandes IR, Russo FB, Freitas BC, Dias JLM, Guimarães KP, Benazzato C, Almeida N, Pignatari GC, Romero S, et al. The Brazilian Zika virus strain causes birth defects in experimental models. Nature (2016) 534:267-271. doi:10.1038/nature18296

6. Cao-Lormeau V-M, Blake A, Mons S, Lastère S, Roche C, Vanhomwegen J, Dub T, Baudouin

7. Faria NR, Azevedo R do S da S, Kraemer MUG, Souza R, Cunha MS, Hill SC, Thézé J,

9. Hirsch AJ, Smith JL, Haese NN, Broeckel RM, Parkins CJ, Kreklywich C, DeFilippis VR, Denton M, Smith PP, Messer WB, et al. Zika Virus infection of rhesus macaques leads to viral persistence in multiple tissues. PLoS Pathog (2017) 13:e1006219. doi:10.1371/journal.ppat.1006219

14. Bowen JR, Quicke KM, Maddur MS, O’Neal JT, McDonald CE, Fedorova NB, Puri V,

10. Osuna CE, Lim SY, Deleage C, Griffin BD, Stein D, Schroeder LT, Omange R, Best K, Luo $\mathrm{M}$, Hraber PT, et al. Zika viral dynamics and shedding in rhesus and cynomolgus macaques. Nat Med (2016) 22:1448-1455. doi:10.1038/nm.4206

11. O’Connor MA, Tisoncik-Go J, Lewis TB, Miller CJ, Bratt D, Moats CR, Edlefsen PT, Smedley J, Klatt NR, Gale M, et al. Early cellular innate immune responses drive Zika viral persistence and tissue tropism in pigtail macaques. Nat Commun (2018) 9:3371. doi:10.1038/s41467-018-05826-w

12. Kam Y-W, Leite JA, Lum FM, Tan JJL, Lee B, Judice CC, De Toledo Teixeira DA, AndreataSantos R, Vinolo MA, Angerami R, et al. Specific Biomarkers Associated With Neurological Complications and Congenital Central Nervous System Abnormalities From Zika VirusInfected Patients in Brazil. J Infect Dis (2017) 216:172-181. doi:10.1093/infdis/jix261

13. Lum FM, Lye DCB, Tan JJL, Lee B, Chia PY, Chua TK, Amrun SN, Kam YW, Yee WX, Ling WP, et al. Longitudinal Study of Cellular and Systemic Cytokine Signatures to Define the Dynamics of a Balanced Immune Environment During Disease Manifestation in Zika Virus-Infected Patients. J Infect Dis (2018) 218:814-824. doi:10.1093/infdis/jiy225

Shabman RS, Pulendran B, Suthar MS. Zika Virus Antagonizes Type I Interferon Responses during Infection of Human Dendritic Cells. PLoS Pathog (2017) 13:e1006164. doi:10.1371/journal.ppat.1006164

15. Foo S-S, Chen W, Chan Y, Bowman JW, Chang L-C, Choi Y, Yoo JS, Ge J, Cheng G, Bonnin A, et al. Asian Zika virus strains target CD14+ blood monocytes and induce M2-skewed immunosuppression during pregnancy. Nat Microbiol (2017) 2:1558-1570. 
16. Michlmayr D, Andrade P, Gonzalez K, Balmaseda A, Harris E. CD14+CD16+ monocytes are the main target of Zika virus infection in peripheral blood mononuclear cells in a paediatric study in Nicaragua. Nat Microbiol (2017) 2:1462-1470. doi:10.1038/s41564-017-0035-0

17. Vielle NJ, Zumkehr B, García-Nicolás O, Blank F, Stojanov M, Musso D, Baud D, Summerfield A, Alves MP. Silent infection of human dendritic cells by African and Asian strains of Zika virus. Sci Rep (2018) 8:5440. doi:10.1038/s41598-018-23734-3

18. Hirsch AJ, Roberts VHJ, Grigsby PL, Haese N, Schabel MC, Wang X, Lo JO, Liu Z, Kroenke $\mathrm{CD}$, Smith JL, et al. Zika virus infection in pregnant rhesus macaques causes placental dysfunction and immunopathology. Nat Commun (2018) 9:263. doi:10.1038/s41467-01702499-9

20. Manangeeswaran M, Ireland DDC, Verthelyi D. Zika (PRVABC59) Infection Is Associated with T cell Infiltration and Neurodegeneration in CNS of Immunocompetent Neonatal C57Bl/6 Mice. PLoS Pathog (2016) 12:e1006004. doi:10.1371/journal.ppat.1006004

21. Tripathi S, Balasubramaniam VRMT, Brown JA, Mena I, Grant A, Bardina S V., Maringer K, Schwarz MC, Maestre AM, Sourisseau M, et al. A novel Zika virus mouse model reveals strain specific differences in virus pathogenesis and host inflammatory immune responses.

22. Ayala-Nunez NV, Follain G, Delalande F, Hirschler A, Partiot E, Hale GL, Bollweg BC, favoring viral dissemination to neural cells. Nat Commun (2019) 10:4430. doi:10.1038/s41467-019-12408-x

23. McDonald EM, Anderson J, Wilusz J, Ebel GD, Brault AC. Zika virus replication in myeloid cells during acute infection is vital to viral dissemination and pathogenesis in a mouse model. J Virol (2020) 94:e00838-20. doi:10.1128/JVI.00127-20 
555

556

557

558

559

560

561

562

563

564

565

566

567

568

569

570

571

572

573

574

575

576

577

578

579

580

581

582

583

584

585

586

587

588

589

590

591

592

593
27. de Noronha L, Zanluca C, Azevedo MLV, Luz KG, dos Santos CND. Zika virus damages the human placental barrier and presents marked fetal neurotropism. Mem Inst Oswaldo Cruz (2016) 111:287-293. doi:10.1590/0074-02760160085

28. Brinkmann V, Reichard U, Goosmann C, Fauler B, Uhlemann Y, Weiss DS, Weinrauch Y, Zychlinsky A. Neutrophil Extracellular Traps Kill Bacteria. Science (80- ) (2004) 303:15321535. doi:10.1126/science.1092385

29. Kruger P, Saffarzadeh M, Weber ANR, Rieber N, Radsak M, von Bernuth H, Benarafa C, Roos D, Skokowa J, Hartl D. Neutrophils: Between Host Defence, Immune Modulation, and Tissue Injury. PLoS Pathog (2015) 11:e1004651. doi:10.1371/journal.ppat.1004651

30. Duffy D, Perrin H, Abadie V, Benhabiles N, Boissonnas A, Liard C, Descours B, Reboulleau D, Bonduelle O, Verrier B, et al. Neutrophils Transport Antigen from the Dermis to the Bone Marrow, Initiating a Source of Memory CD8+ T Cells. Immunity (2012) 37:917-929. doi:10.1016/j.immuni.2012.07.015

31. Hufford MM, Richardson G, Zhou H, Manicassamy B, García-Sastre A, Enelow RI, Braciale TJ. Influenza-Infected Neutrophils within the Infected Lungs Act as Antigen Presenting Cells for Anti-Viral CD8+ T Cells. PLoS One (2012) 7:e46581. doi:10.1371/journal.pone.0046581

32. Paul AM, Acharya D, Duty L, Thompson EA, Le L, Stokic DS, Leis AA, Bai F. Osteopontin facilitates West Nile virus neuroinvasion via neutrophil "Trojan horse" transport. Sci Rep (2017) 7:4722. doi:10.1038/s41598-017-04839-7

33. Bai F, Kong K, Dai J, Qian F, Zhang L, Brown CR, Fikrig E, Montgomery RR. A Paradoxical Role for Neutrophils in the Pathogenesis of West Nile Virus. J Infect Dis (2010) 202:18041812. doi: $10.1086 / 657416$

34. Strottmann DM, Zanluca C, Mosimann ALP, Koishi AC, Auwerter NC, Faoro H, Cataneo AHD, Kuczera D, Wowk PF, Bordignon J, et al. Genetic and biological characterization of Zika virus isolates from different Brazilian regions. Mem Inst Oswaldo Cruz (2019) 114:e190150. doi:10.1590/0074-02760190150

35. Donald CL, Brennan B, Cumberworth SL, Rezelj V V., Clark JJ, Cordeiro MT, Freitas de Oliveira França R, Pena LJ, Wilkie GS, Da Silva Filipe A, et al. Full Genome Sequence and sfRNA Interferon Antagonist Activity of Zika Virus from Recife, Brazil. PLoS Negl Trop Dis (2016) 10:e0005048. doi:10.1371/journal.pntd.0005048

36. Dick GWA, Kitchen SF, Haddow AJ. Zika virus isolation and serological specificity. Trans $R$ Soc Trop Med Hyg (1952) 46:509-520.

37. Cataneo AHD, Kuczera D, Koishi AC, Zanluca C, Silveira GF, Arruda TB de, Suzukawa AA, Bortot LO, Dias-Baruffi M, Verri WA, et al. The citrus flavonoid naringenin impairs the in vitro infection of human cells by Zika virus. Sci Rep (2019) 9:16348. doi:10.1038/s41598-01952626-3

38. Dejarnac O, Hafirassou ML, Chazal M, Versapuech M, Gaillard J, Perera-Lecoin M, UmanaDiaz C, Bonnet-Madin L, Carnec X, Tinevez JY, et al. TIM-1 Ubiquitination Mediates Dengue Virus Entry. Cell Rep (2018) 23:1779-1793. doi:10.1016/j.celrep.2018.04.013 
594

595

596

597

598

599

600

601

602

603

604

605

606

607

608

609

610

611

612

613

614

615

616

617

618

619

620

621

622

623

624

625

626

627

628

629

630

631

632

39. Lanciotti RS, Kosoy OL, Laven JJ, Velez JO, Lambert AJ, Johnson AJ, Stanfield SM, Duffy MR. Genetic and Serologic Properties of Zika Virus Associated with an Epidemic, Yap State, Micronesia, 2007. Emerg Infect Dis (2008) 14:1232-1239. doi:10.3201/eid1408.080287

40. Emery SL, Erdman DD, Bowen MD, Newton BR, Winchell JM, Meyer RF, Tong S, Cook BT, Holloway BP, McCaustland KA, et al. Real-Time Reverse Transcription-Polymerase Chain Reaction Assay for SARS-associated Coronavirus. Emerg Infect Dis (2004) 10:311-316. doi:10.3201/eid1002.030759

41. Sousa-Rocha D, Thomaz-Tobias M, Diniz LFA, Souza PSS, Pinge-Filho P, Toledo KA. Trypanosoma cruzi and its Soluble Antigens Induce NET Release by Stimulating Toll-Like Receptors. PLoS One (2015) 10:e0139569. doi:10.1371/journal.pone.0139569

42. Porto BN, Alves LS, Fernández PL, Dutra TP, Figueiredo RT, Graça-Souza A V., Bozza MT. Heme Induces Neutrophil Migration and Reactive Oxygen Species Generation through Signaling Pathways Characteristic of Chemotactic Receptors. J Biol Chem (2007) 282:2443024436. doi:10.1074/jbc.M703570200

43. Mayadas TN, Cullere X, Lowell CA. The Multifaceted Functions of Neutrophils. Anпи Rev Pathol Mech Dis (2014) 9:181-218. doi:10.1146/annurev-pathol-020712-164023

44. Sabroe I, Prince LR, Jones EC, Horsburgh MJ, Foster SJ, Vogel SN, Dower SK, Whyte MKB. Selective Roles for Toll-Like Receptor (TLR)2 and TLR4 in the Regulation of Neutrophil Activation and Life Span. J Immunol (2003) 170:5268-5275. doi:10.4049/jimmunol.170.10.5268

45. Kishimoto T, Jutila M, Berg E, Butcher E. Neutrophil Mac-1 and MEL-14 Adhesion Proteins Inversely Regulated by Chemotactic Factors. Science (80- ) (1989) 245:1238-1241. doi:10.1126/science. 2551036

46. Zhou X, Gao XP, Fan J, Liu Q, Anwar KN, Frey RS, Malik AB. LPS activation, of Toll-like receptor 4 signals CD11b/CD18 expression in neutrophils. Am J Physiol - Lung Cell Mol Physiol (2005) 288:L655-62. doi:10.1152/ajplung.00327.2004

47. Papayannopoulos V. Neutrophil extracellular traps in immunity and disease. Nat Rev Immunol (2018) 18:134-147. doi:10.1038/nri.2017.105

48. Fischer MA, Davies ML, Reider IE, Heipertz EL, Epler MR, Sei JJ, Ingersoll MA, van Rooijen N, Randolph GJ, Norbury CC. CD11b+, Ly6G+ Cells Produce Type I Interferon and Exhibit Tissue Protective Properties Following Peripheral Virus Infection. PLoS Pathog (2011) 7:e1002374. doi:10.1371/journal.ppat.1002374

49. Tate MD, Ioannidis LJ, Croker B, Brown LE, Brooks AG, Reading PC. The Role of Neutrophils during Mild and Severe Influenza Virus Infections of Mice. PLoS One (2011) 6:e17618. doi:10.1371/journal.pone.0017618

50. Saitoh T, Komano J, Saitoh Y, Misawa T, Takahama M, Kozaki T, Uehata T, Iwasaki H, Omori H, Yamaoka S, et al. Neutrophil Extracellular Traps Mediate a Host Defense Response to Human Immunodeficiency Virus-1. Cell Host Microbe (2012) 12:109-116. doi:10.1016/j.chom.2012.05.015 
51. Muraro SP, De Souza GF, Gallo SW, Da Silva BK, De Oliveira SD, Vinolo MAR, Saraiva

634

635

636 EM, Porto BN. Respiratory Syncytial Virus induces the classical ROS-dependent NETosis through PAD-4 and necroptosis pathways activation. Sci Rep (2018) 8:14166. doi:10.1038/s41598-018-32576-y

52. Middleton EA, He XY, Denorme F, Campbell RA, Ng D, Salvatore SP, Mostyka M, BaxterStoltzfus A, Borczuk AC, Loda M, et al. Neutrophil Extracellular Traps (NETs) Contribute to Immunothrombosis in COVID-19 Acute Respiratory Distress Syndrome. Blood (2020) 136:1169-1179. doi:10.1182/blood.2020007008

53. Heit B, Jones G, Knight D, Antony JM, Gill MJ, Brown C, Power C, Kubes P. HIV and Other Lentiviral Infections Cause Defects in Neutrophil Chemotaxis, Recruitment, and Cell Structure: Immunorestorative Effects of Granulocyte-Macrophage Colony-Stimulating Factor. J Immunol (2006) 177:6405-6414. doi:10.4049/jimmunol.177.9.6405

54. Chen J, Yang YF, Yang Y, Zou P, Chen J, He Y, Shui SL, Cui YR, Bai R, Liang YJ, et al. AXL promotes Zika virus infection in astrocytes by antagonizing type I interferon signalling. Nat Microbiol (2018) 3:302-309. doi:10.1038/s41564-017-0092-4

55. Giraldo DM, Hernandez JC, Velilla P, Urcuqui-Inchima S. HIV-1-neutrophil interactions trigger neutrophil activation and Toll-like receptor expression. Immunol Res (2016) 64:93103. doi:10.1007/s12026-015-8691-8

56. Hiroki CH, Toller-Kawahisa JE, Fumagalli MJ, Colon DF, Figueiredo LTM, Fonseca BALD, Franca RFO, Cunha FQ. Neutrophil Extracellular Traps Effectively Control Acute Chikungunya Virus Infection. Front Immunol (2020) 10:3108. doi:10.3389/fimmu.2019.03108

58. Bos S, Poirier-Beaudouin B, Seffer V, Manich M, Mardi C, Desprès P, Gadea G, Gougeon MNS1-Dependent Triggering of CD303 (BDCA-2) Signaling. Front Immunol (2020) 11:582061. doi:10.3389/fimmu.2020.582061

662 
672

673

674

675

676

677

678

679

680

681

682

683

684

685

686

687

688

689

690

691

692

693

694

695

696

697

698

699

700

701

702

703

704

705

706

707

708

709

710

YH, Lee CYP, et al. Immunological observations and transcriptomic analysis of trimesterspecific full-term placentas from three Zika virus-infected women. Clin Transl Immunol (2019) 8:e1082. doi:10.1002/cti2.1082

63. Nguyen SM, Antony KM, Dudley DM, Kohn S, Simmons HA, Wolfe B, Salamat MS, Teixeira LBC, Wiepz GJ, Thoong TH, et al. Highly efficient maternal-fetal Zika virus transmission in pregnant rhesus macaques. PLoS Pathog (2017) 13:e1006378. doi:10.1371/journal.ppat.1006378

64. Wang W, Li G, De W, Luo Z, Pan P, Tian M, Wang Y, Xiao F, Li A, Wu K, et al. Zika virus infection induces host inflammatory responses by facilitating NLRP3 inflammasome assembly and interleukin-1 $\beta$ secretion. Nat Commun (2018) 9:106. doi:10.1038/s41467-017-02645-3

65. Frumence E, Roche M, Krejbich-Trotot P, El-Kalamouni C, Nativel B, Rondeau P, Missé D, Gadea G, Viranaicken W, Desprès P. The South Pacific epidemic strain of Zika virus replicates efficiently in human epithelial A549 cells leading to IFN- $\beta$ production and apoptosis induction. Virology (2016) 493:217-226. doi:10.1016/j.virol.2016.03.006

66. Hattar K, Franz K, Ludwig M, Sibelius U, Wilhelm J, Lohmeyer J, Savai R, Subtil FSB, Dahlem G, Eul B, et al. Interactions between neutrophils and non-small cell lung cancer cells: enhancement of tumor proliferation and inflammatory mediator synthesis. Cancer Immunol Immunother (2014) 63:1297-1306. doi:10.1007/s00262-014-1606-z

67. Grandel U, Heygster D, Sibelius U, Fink L, Sigel S, Seeger W, Grimminger F, Hattar K. Amplification of Lipopolysaccharide-Induced Cytokine Synthesis in Non-Small Cell Lung Cancer/Neutrophil Cocultures. Mol Cancer Res (2009) 7:1729-1735. doi:10.1158/15417786.MCR-09-0048

68. Serrao KL, Fortenberry JD, Owens ML, Harris FL, Brown LAS. Neutrophils induce apoptosis of lung epithelial cells via release of soluble Fas ligand. Am J Physiol - Lung Cell Mol Physiol (2001) 280:L298-305. doi:10.1152/ajplung.2001.280.2.1298

69. Deng Y, Herbert JA, Robinson E, Ren L, Smyth RL, Smith CM. Neutrophil-Airway Epithelial Interactions Result in Increased Epithelial Damage and Viral Clearance during Respiratory Syncytial Virus Infection. J Virol (2020) 94:e02161-19. doi:10.1128/jvi.02161-19

70. Pingen M, Bryden SR, Pondeville E, Schnettler E, Kohl A, Merits A, Fazakerley JK, Graham GJ, McKimmie CS. Host Inflammatory Response to Mosquito Bites Enhances the Severity of Arbovirus Infection. Immunity (2016) 44:1455-1469. doi:10.1016/j.immuni.2016.06.002

71. Xu D, Wang P, Yang J, Qian Q, Li M, Wei L, Xu W. Gr-1+ Cells Other Than Ly6G+ Neutrophils Limit Virus Replication and Promote Myocardial Inflammation and Fibrosis Following Coxsackievirus B3 Infection of Mice. Front Cell Infect Microbiol (2018) 8:157. doi:10.3389/fcimb.2018.00157

72. Kirsebom F, Michalaki C, Agueda-Oyarzabal M, Johansson C. Neutrophils do not impact viral load or the peak of disease severity during RSV infection. Sci Rep (2020) 10:1110. doi:10.1038/s41598-020-57969-w

73. Cortjens B, Lutter R, Boon L, Bem RA, Van Woensel JBM. Pneumovirus-Induced Lung 
Disease in Mice Is Independent of Neutrophil-Driven Inflammation. PLoS One (2016)

74. Wojtasiak M, Pickett DL, Tate MD, Londrigan SL, Bedoui S, Brooks AG, Reading PC. Depletion of Gr-1+, but not Ly6G+, immune cells exacerbates virus replication and disease in an intranasal model of herpes simplex virus type 1 infection. J Gen Virol (2010) 91:21582166. doi:10.1099/vir.0.021915-0

75. Seo SU, Kwon HJ, Ko HJ, Byun YH, Seong BL, Uematsu S, Akira S, Kweon MN. Type I Interferon Signaling Regulates Ly6Chi Monocytes and Neutrophils during Acute Viral Pneumonia in Mice. PLoS Pathog (2011) 7:e1001304. doi:10.1371/journal.ppat.1001304

76. Furuya Y, Steiner D, Metzger DW. Does type I interferon limit protective neutrophil responses during pulmonary Francisella tularensis infection? Front Immunol (2014) 5:355. doi:10.3389/fimmu.2014.00355

77. Grant A, Ponia SS, Tripathi S, Balasubramaniam V, Miorin L, Sourisseau M, Schwarz MC, Sánchez-Seco MP, Evans MJ, Best SM, et al. Zika Virus Targets Human STAT2 to Inhibit Type I Interferon Signaling. Cell Host Microbe (2016) 19:882-890. doi:10.1016/j.chom.2016.05.009 


\section{Figure Captions}

728 Figure 1. ZIKV do not replicate in human neutrophils. (A) Neutrophils morphological features after 729 isolation shown by flow cytometry and microscopy (bright-field, bar $=25 \mu \mathrm{m}$, magnification $=$

730 100x.). (B) The cells were stimulated in vitro during 2 hours with ZIKV BR 2015/15261, ZIKV

731 PE243, ZIKV MR766 (1 MOI), or mock (C6/36 cells conditioned media in equivalent volume of

732 ZIKV strains). Then, neutrophils were washed to remove the stimuli (indicated by $\boldsymbol{\nabla}$ ), and evaluated

733 right after that (2 hours), and at 6,12 and 24 hours after stimulation. When indicated, neutrophils

734 were treated with trypsin after the wash step at 2 hours of stimulation with ZIKV strains. (C)

735 Immunostaining of neutrophils with 4G2 (E protein; green) at 24 hours after ZIKV PE243 (a-d) or

736 mock (e-h) stimulation. Nuclei (blue) were stained with Vybrant DyeCycleViolet. Merge of these

737 stainings and the bright-field colocalization are also shown. C6/36 cells (1-p) were used as an

738 infection positive control (bar $=50 \mu \mathrm{m}$, magnification $=40 \mathrm{x}$.) (D) Histograms showing 4G2 intensity

739 of fluorescence in neutrophils and C6/36 cells at 24 hours after mock and ZIKV PE243 stimulation as

740 measured through flow cytometry. Infected-unstained cells were used as a negative fluorescence

741 control. (E) Histograms showing AXL receptor intensity of fluorescence in neutrophils and A549

742 cells. An isotype control antibody was used as a negative fluorescence control. One representative

743 result of three independent experiments is shown. (F) RNA levels of ZIKV strains in neutrophils at 2,

7446,12 and 24 hours after stimulation. (G) ZIKV loads on neutrophil culture supernatant at the same

745 time after stimulation with ZIKV strains. The dashed line named input represents the mean of the

746 titers of the three ZIKV strains still detected on the supernatant after the stimuli removal after 2 hours

747 of stimulation. (H) RNA levels of ZIKV PE243 detected in neutrophils treated or not with trypsin

748 after 2 hours of stimulation. Bars indicate standard error of the mean (SEM). Three-four independent

749 experiments are shown $(\mathrm{n}=9-15)$. The asterisk $(*)$ denotes statistical difference between 6 and 12

750 hours of the ZIKV PE243 stimulation $(\mathrm{F})$.

751 Figure 2. ZIKV mildly regulates CD62L expression in human neutrophils, but does not stimulate

752 cytokines, elastase, and reactive oxygen species production by these cells. (A) Contour plots

753 depicting the frequency of neutrophils $\mathrm{CD} 16^{+} \mathrm{CD} 11 \mathrm{~b}^{+}$and $\mathrm{CD} 16^{+} \mathrm{CD} 62 \mathrm{~L}^{+}$and the fluorescence

754 intensity of CD11b and CD62L molecules inside these populations at 6 hours after stimulation with

755 mock, LPS (100 ng/mL) or ZIKV PE243 (1 MOI). This time point and strain were chosen as a

756 representative of these results. Isotype control antibodies were used as a negative fluorescence

757 control to set the gates. A representative result of chloromethyl- $\mathrm{H}_{2}$ DCFDA (CM- $\left.\mathrm{H}_{2} \mathrm{DCFDA}\right)$ 
758 fluorescence in the total neutrophil population at 6 hours after stimulation with mock, PMA (16 nM)

759 or ZIKV PE243 is also shown. (B) Frequency of neutrophils CD16 ${ }^{+} \mathrm{CD} 11 \mathrm{~b}^{+}$and the mean

760 fluorescence intensity (MFI) of CD11b in that population at 2, 6 and 12 hours after stimulation with

761 mock, LPS or ZIKV strains (1 MOI). The dashed line represents the measurements right after

762 neutrophil obtention from blood (0 hours). (C) Same analysis as in (B) applied to the CD62L

763 molecule. (D) IL-8 levels in neutrophil culture supernatant at 6 and 12 hours after stimulation. (E)

764 Elastase levels in neutrophil culture supernatant at 6 hours after stimulation. (F) Frequency of

765 neutrophils $\mathrm{CM}-\mathrm{H}_{2} \mathrm{DCFDA}^{+}$at 2 and 6 hours after stimulation. Bars indicate SEM. Two-three

766 independent experiments are shown $(n=6-12)$. The asterisk $(*)$ denotes statistical difference between

767 mock and LPS (B-E) or PMA (F), and the number sign (\#) between mock and all the three ZIKV

768 strains in that time point (B-C).

769 Figure 3. ZIKV do not induce NETs, and are not captured by the DNA trap. (A) Immunostaining of 770 neutrophils DNA (Vybrant DyeCycleViolet, blue) and acetyl-histone H3 (green) after 5 hours of 771 stimulation with mock (a-d), PMA (160 nM) (e-h) or ZIKV PE243 (1 MOI) (i-1). ZIKV PE243 was

772 chosen as representative of the ZIKV strains' effects. Merge of these stainings and the bright-field

773 colocalization are also shown $(\mathrm{bar}=50 \mu \mathrm{m}$, magnification $=60 \mathrm{x})$. One representative of three

774 independent experiments is shown. (B) Free double stranded DNA (dsDNA) on neutrophil culture

775 supernatant after 5 hours of stimulation with mock, PMA or ZIKV strains (1 MOI). (C) ZIKV strains

776 loads on neutrophil culture supernatant after 1 hour in the presence or absence of NETs induced by

777 PMA stimulation during 5 hours. Bars indicate SEM. Two-three independent experiments are shown

778 (n=6-9). The asterisk (*) denotes statistical difference between mock and PMA (B).

779 Figure 4. Human neutrophil does not impair ZIKV infectivity. Frequency of 4G2+ A549 cells at 36 780 hours after infection with ZIKV strains (1 MOI) previously incubated 6 hours in the absence (ZIKV) 781 or presence (ZIKV $+\mathrm{N} \varnothing)$ of neutrophils. ZIKV PE243 is shown as a representative of the ZIKV 782 strains' effects on the flow cytometry plots. The mock condition was used as a negative fluorescence 783 control. Bars indicate SEM. Three independent experiments are shown $(n=9)$. $(\boldsymbol{\nabla})$ indicates the 784 moment A549 cells were washed to remove the virus. $\mathrm{N} \varnothing=$ neutrophils.

785 Figure 5. ZIKV infection in human primary cells does not induce high levels IL-8 to promote 786 migration of human neutrophils. (A) IL-8 levels in mdDCs and PBMCs culture supernatant at 24 and 78748 hours after stimulation with mock, LPS (100 ng/mL), or ZIKV strains (1 MOI). (B) Chemotactic 788 index of neutrophils after 2 hours of stimulation with 1,000 or $50,000 \mathrm{pg}$ of rhIL-8, or the supernatant 
of A549 cells culture pre-infected with ZIKV PE243 for 48 hours. Bars indicate SEM. Two-three independent experiments are shown $(n=6-9)$. The asterisk $\left(^{*}\right)$ denotes statistical difference between mock and LPS, and the number sign (\#) between mock and all the three ZIKV strains in the time point.

793 Figure 6. Human neutrophils reduce ZIKV infection in A549 cells by contact. Flow cytometry plots depicting the frequency of 4G2 ${ }^{+}$A549 cells at 18 hours post-infection with ZIKV PE243 (1 MOI). Cells were infected for 2 hours in the absence of neutrophils (ZIKV), presence of neutrophils (ZIKV $+\mathrm{N} \emptyset$ ), or presence of trypsin pre-treated neutrophils (ZIKV + NØ-trypsin). ZIKV PE243 is shown as a representative of the ZIKV strains' effects. Mock condition was used as a negative fluorescence control. (B) Frequency of 4G2 ${ }^{+}$A549 cells at 18 hours post-infection with ZIKV strains (1 MOI) in the absence or presence of neutrophils. (C) Frequency of viable A549 cells (annexin $\mathrm{V}^{-} 7-\mathrm{AAD}^{-}$) after

80018 hours of infection with ZIKV PE243 (1 MOI) in the absence or presence to neutrophils during the 801 infection. (D) Frequency of neutrophils $\mathrm{CD}_{16} \mathrm{CD}^{+} 1 \mathrm{~b}^{+}$and the mean fluorescence intensity (MFI) of $802 \mathrm{CD} 11 \mathrm{~b}$ in that population after the 2 hours of interaction with A459 cells stimulated with mock or 803 PE243. (E) Same analysis as in (D) applied to the CD62L molecule. (F) Frequency of 4G2 ${ }^{+}$A549 804 cells at 18 hours post-infection with ZIKV PE243 in presence of trypsin pre-treated neutrophils. (G) ZIKV PE243 loads on A549 cells culture supernatant at 18 hours post-infection in presence of trypsin pre-treated neutrophils. Bars indicate SEM. Three-four independent experiments are shown (n =7-15). The asterisk $(*)$ denotes statistical difference between the absence and presence of neutrophils $(\mathrm{B}, \mathrm{F}-\mathrm{G})$ or neutrophils pre-treated with trypsin $(\mathrm{F})$ in the conditions. $(\boldsymbol{\nabla})$ indicates the moment A549 cells were washed to remove the stimuli. $\mathrm{N} \varnothing=$ neutrophils.

810 Figure 7. Trypsin treatment affects the expression of CD62L in neutrophils. (A) Frequency of viable 811 neutrophils (annexin $\mathrm{V}^{-7} \mathrm{AAD}^{-}$) after treatment with trypsin. (B) Contour plots depicting the

812 frequency of neutrophils $\mathrm{CD} 16^{+} \mathrm{CD} 11 \mathrm{~b}^{+}$and $\mathrm{CD} 16^{+} \mathrm{CD} 62 \mathrm{~L}^{+}$and the fluorescence intensity of CD11b 813 and CD62L molecules inside these populations right after isolation from blood (NØ) or in trypsin 814 pre-treated neutrophils (NØ-trypsin). Isotype control antibodies were used as a negative fluorescence 815 control to set the gates. (C) Frequency of neutrophils $\mathrm{CD}_{16} \mathrm{CD}^{+} 1 \mathrm{~b}^{+}$and the mean fluorescence 816 intensity (MFI) of CD11b in that population after treatment with trypsin. (D) Same analysis as in (C) 817 applied to the CD62L molecule. Bars indicate SEM. Two independent experiments are shown $(\mathrm{n}=6-$ 818 7). The asterisk (*) denotes statistical difference between neutrophils treated or not with trypsin (D). $819 \mathrm{~N} \varnothing=$ neutrophils. 
820 Figure 8. Mice neutrophil depletion does not restrict ZIKV relocation to draining lymph nodes. (A)

821 ZIKV loads detected in the pool of both ipsi- and contralateral popliteal (pLN), sciatic (sLN) or

822 lumbar aortic (laLN) lymph nodes per C57BL/6 mice after 10 minutes, 1 and 3 hours of ZIKV PE243

$823\left(5 \times 10^{5} \mathrm{FFU}\right)$ injection in the footpad. (B) Flow cytometry plots depicting the frequency of PMN

824 leukocytes $\mathrm{CD} 11 \mathrm{~b}^{+} \mathrm{Ly} 6 \mathrm{C} / \mathrm{G}^{+}$in the total blood of mice 18 hours post-treatment with PBS or anti-

825 Ly6G antibody $(400 \mu \mathrm{g})$. (C) Frequency of CD11 b ${ }^{+} \mathrm{Ly} 6 \mathrm{C} / \mathrm{G}^{+}$cells in the PMN population in mice

826 treated with PBS, anti-Ly6G, or an isotype antibody for 18 hours. (D) After neutrophil depletion,

827 mice received a footpad subcutaneously injection of PBS or LPS (1000 ng) and 3 hours later, ZIKV

828 PE243 (5×10 5 FFU). One hour later, ipsi- and contralateral pLNs from each mouse were harvested

829 and pooled to determine ZIKV loads. Bars indicate SEM. Three animals per group were used in each

830 experiment. One of three independent experiments is shown. The asterisk (*) denotes statistical

831 difference between PBS and anti-Ly6G groups.

832 Supplementary Figure 1. ZIKV does not affect human neutrophil viability. (A) Contour plots

833 depicting the frequency of annexin $\mathrm{V}^{+}$and 7-AAD ${ }^{+}$in the neutrophils gated population at 6 hours of

834 stimulation with mock, LPS (100 ng/mL), or ZIKV PE243 (1 MOI), as a representative of the results.

835 Mock-unstained condition was used as a negative control of fluorescence to set the gates. (B)

836 Frequency of annexin $\mathrm{V}^{+}$and annexin $\mathrm{V}^{+} 7-\mathrm{AAD}^{+}$neutrophils at 2, 6, 12 and 24 hours of stimulation

837 with mock, LPS, or ZIKV strains (1 MOI). The dashed line represents annexin $\mathrm{V}^{+}$and annexin $\mathrm{V}^{+} / 7$ -

$838 \mathrm{AAD}^{+}$frequency right after neutrophil purification from blood (0 hours). Bars indicate SEM. Three

839 independent experiments are shown $(\mathrm{n}=11)$. The asterisk $(*)$ denotes statistical difference between

840 mock and LPS and the number sign (\#) between mock and all the three ZIKV strains in that time

841 point.

842 Supplementary Figure 2. Human neutrophils reduce ZIKV infection in A549 cells previously

843 infected with ZIKV. Frequency of $4 \mathrm{G}^{+}$A549 cells at 40 hours post-infection with ZIKV strains (1

844 MOI) when neutrophils were added or not to the previously infected A459 cells at 24 hours post-

845 infection and left in contact with the culture for additional 16 hours. Bars indicate SEM. Three-four

846 independent experiments are shown $(n=7-15)$. The asterisk $(*)$ denotes statistical difference between

847 the conditions in which neutrophils were present or absent. $\mathrm{N} \varnothing=$ neutrophils. 


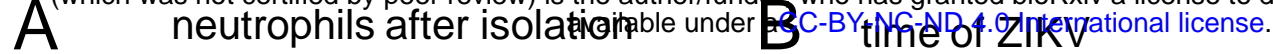

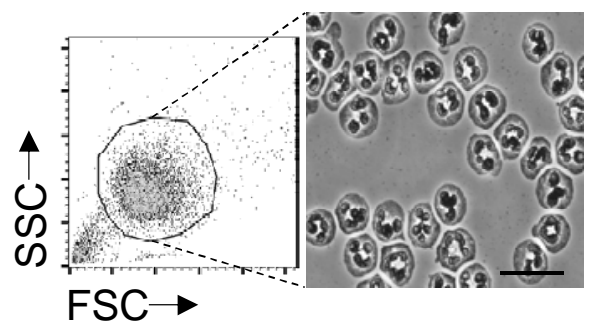

C

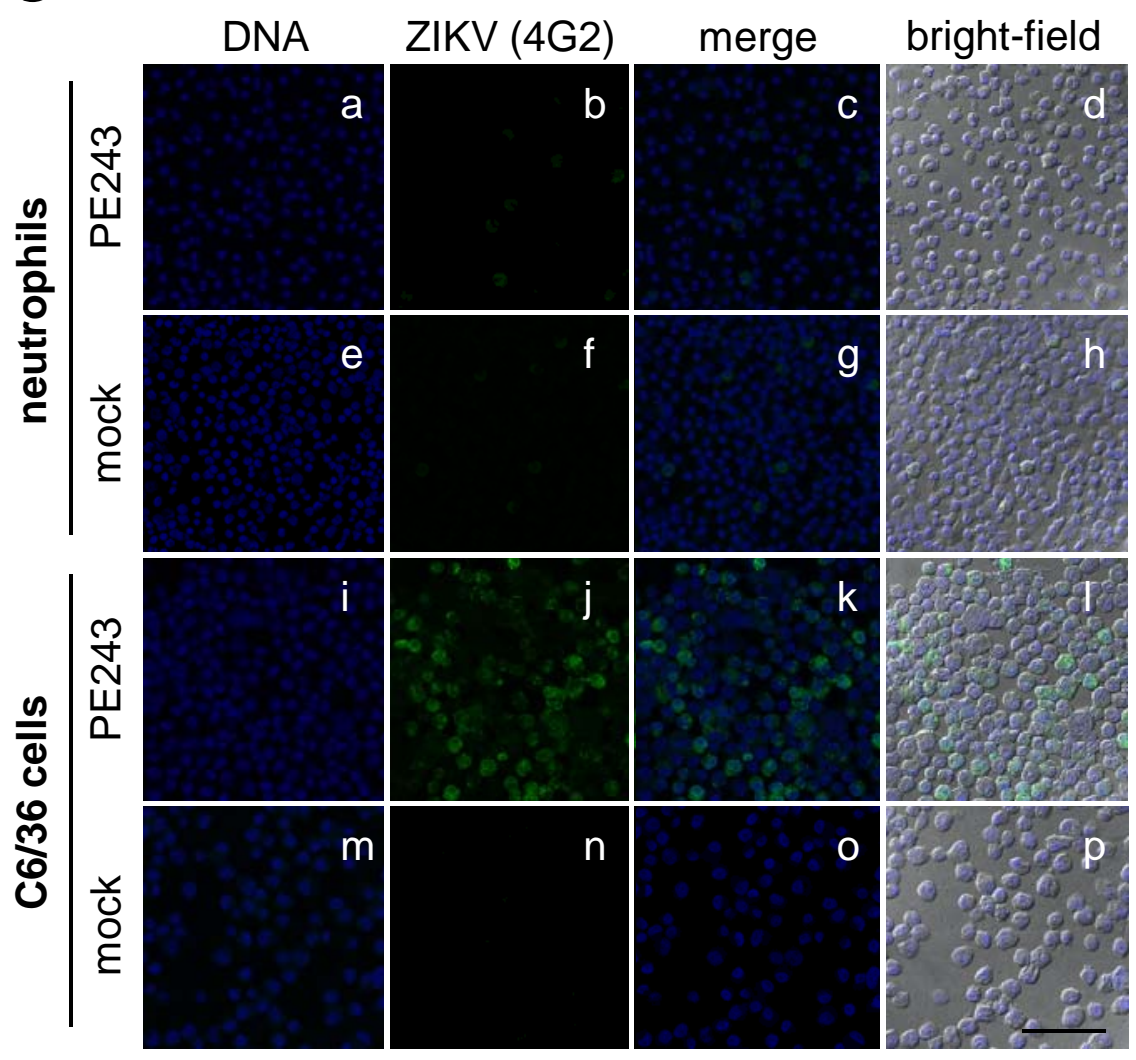

24h after stimulation

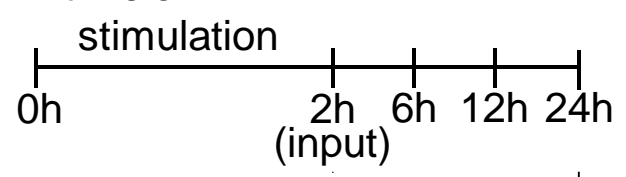

trypsin time after ZIKV
$\mathrm{F}$

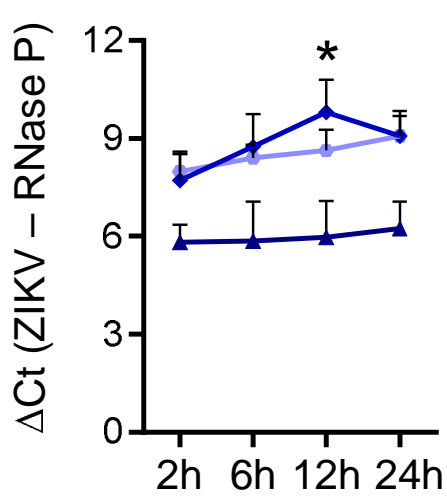

G

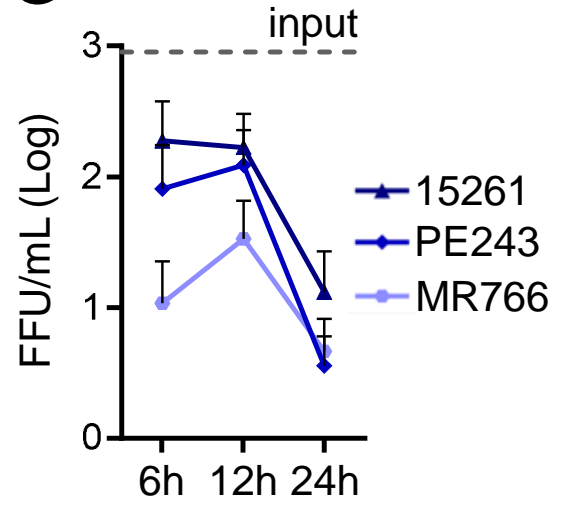

D 24h after stimulation neutrophils $\quad 66 / 36$ cells

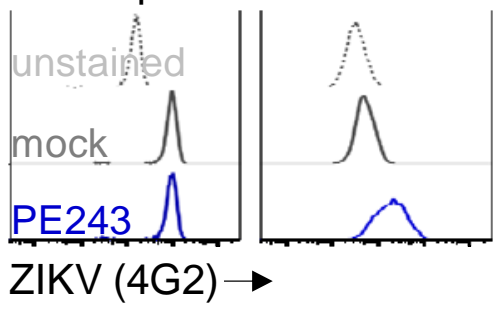

E neutrophils A549 cells

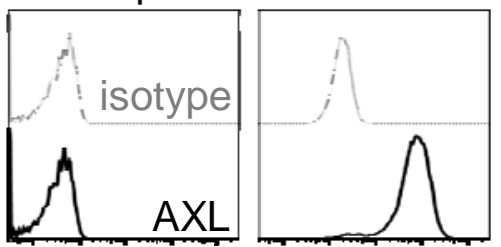

$\mathrm{AXL} \rightarrow$

time after ZIKV stimulation

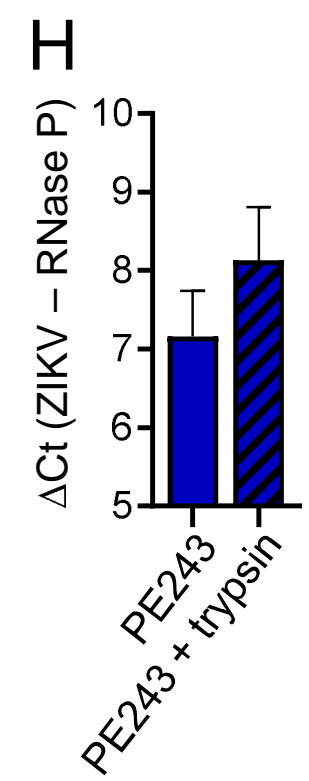


bioRxiv preprint doi: https://doi.org/10.1101/2021.09.26.461875; this version posted September 27, 2021. The copyright holder for this preprint

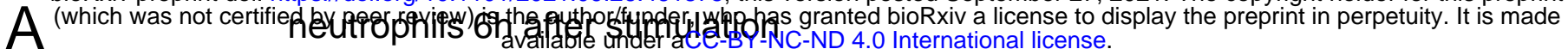
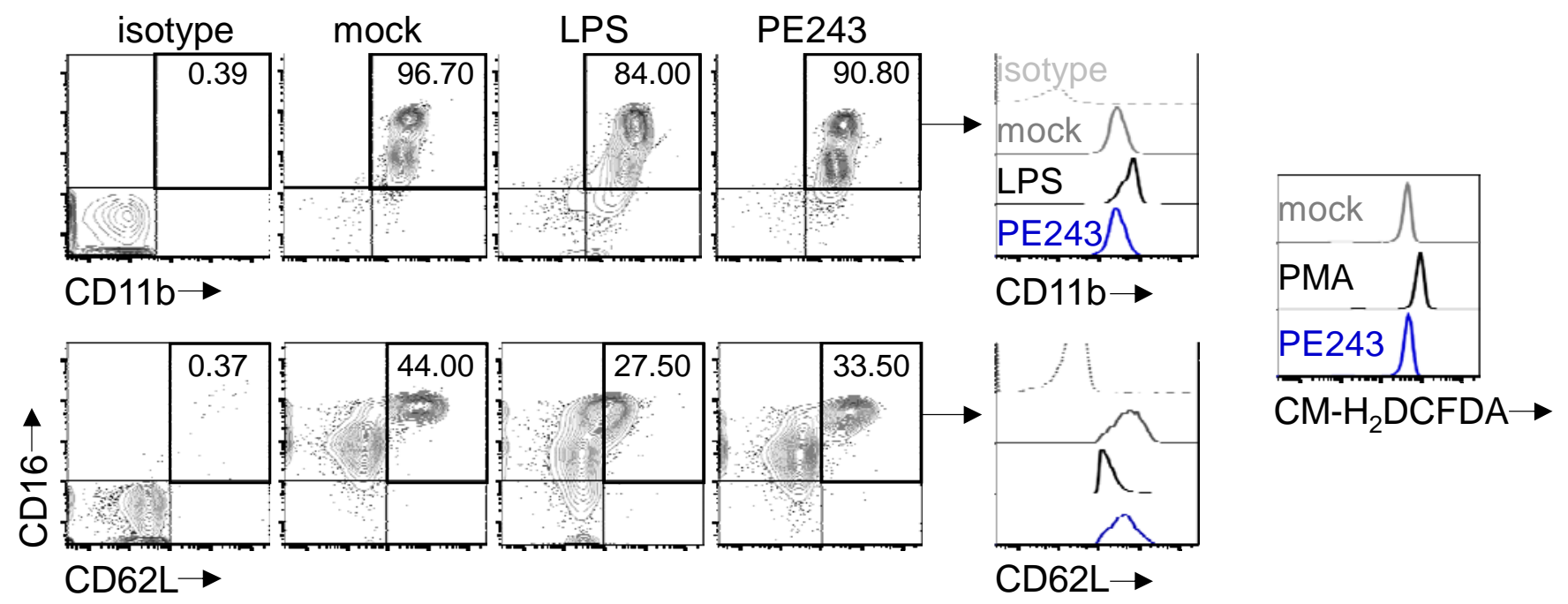

B

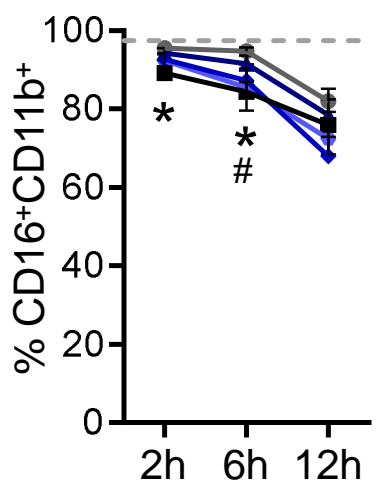

D

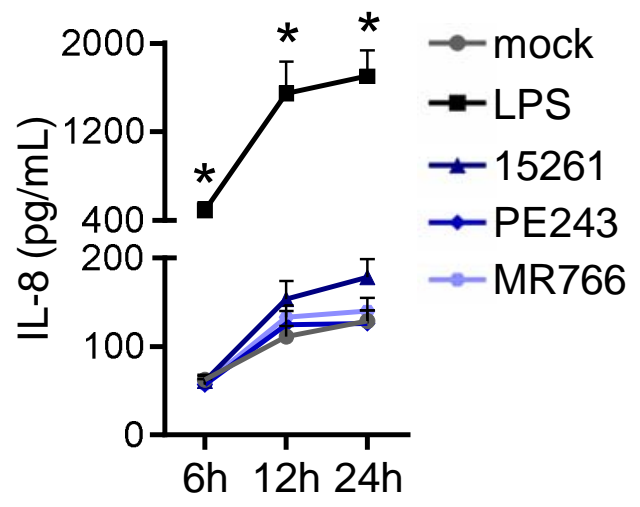

C

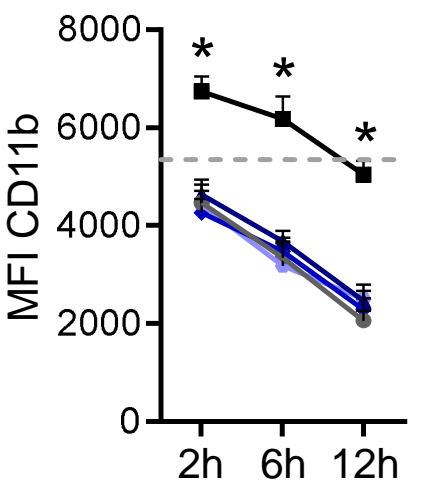

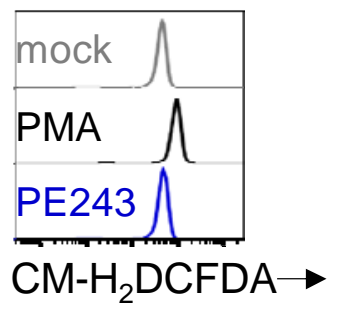

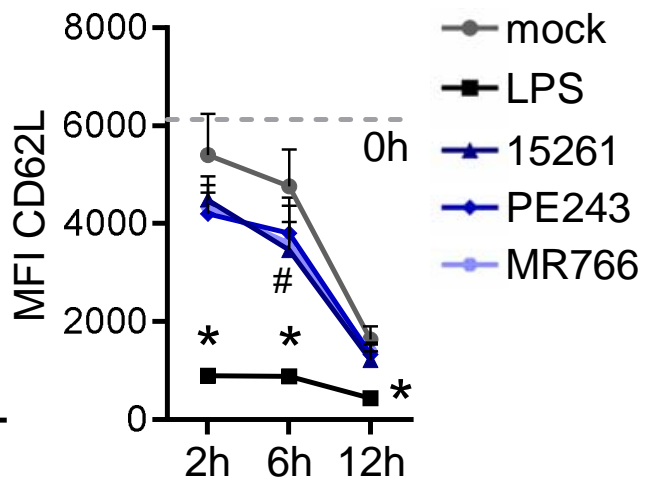

E 6h after stimulation $\mathrm{F}$

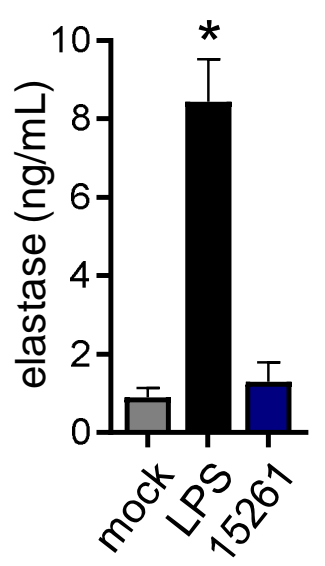

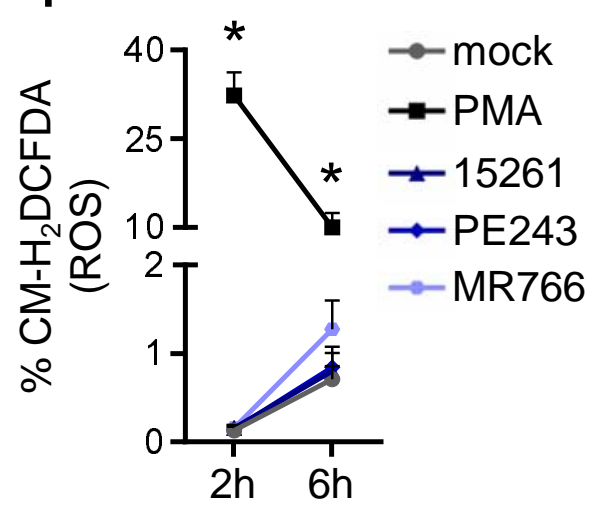




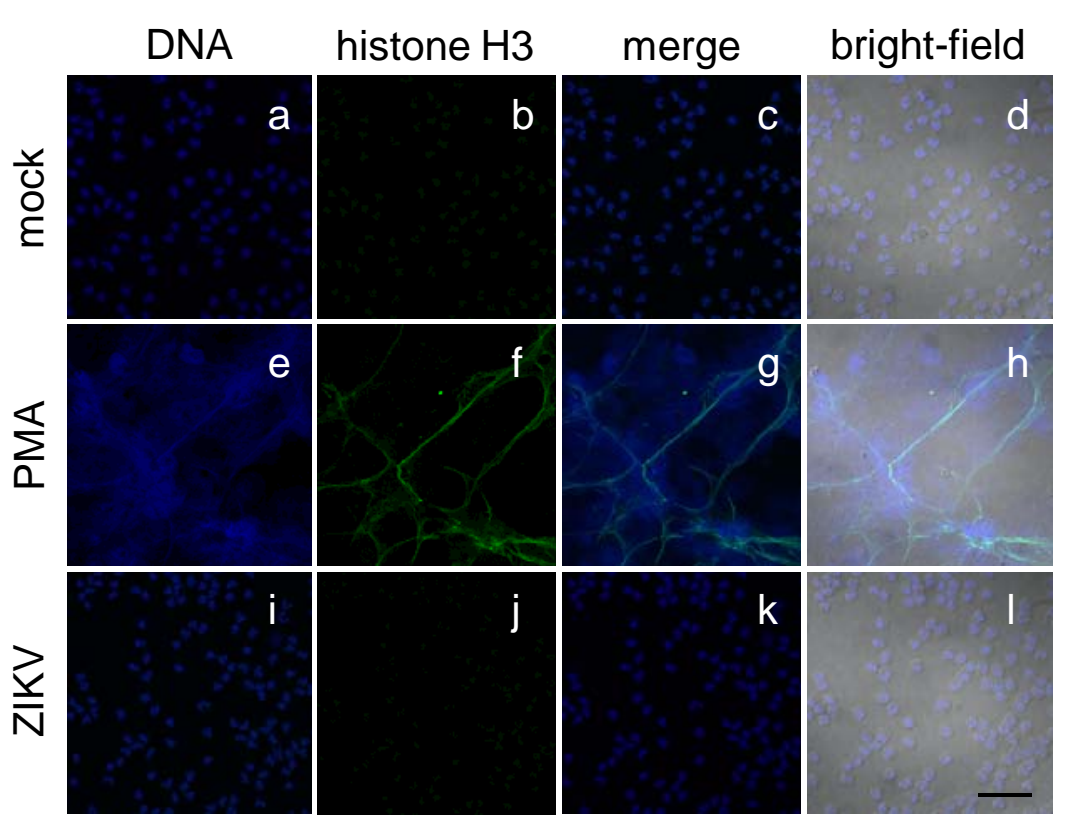

B

$5 \mathrm{~h}$ of stimulation

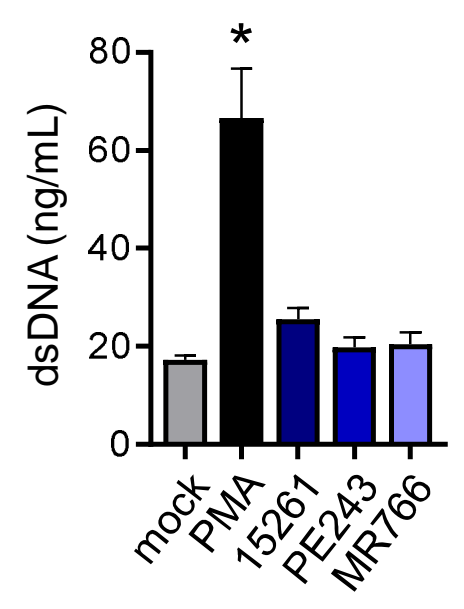

media
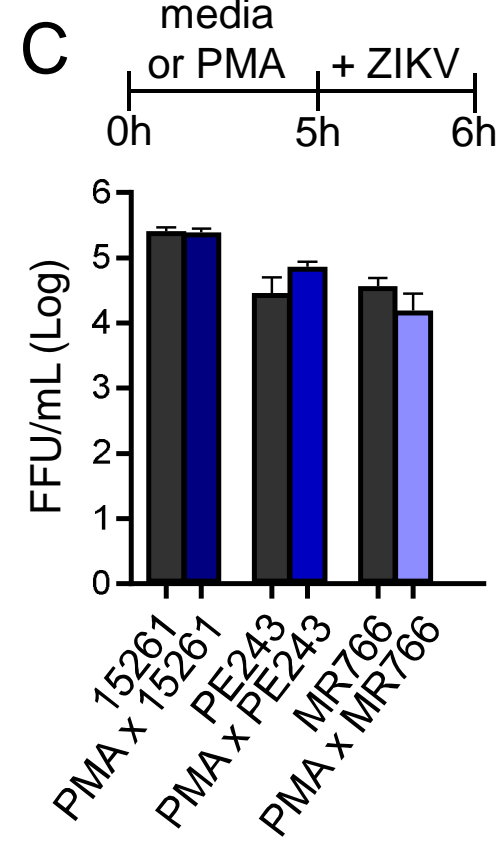
bioRxiv preprint doi: https://doi.org/10.1101/2021.09.26.461875; this version posted September 27, 2021. The copyright holder for this preprint (which was not certified byppergreview) is the author/funder, who has granted bioRxiv a license to display the preprint in perpetuity. It is made Oh $6 \mathrm{~h} \quad$ Oh $2 \mathrm{~h} 36 \mathrm{~h}$

\section{A549 cells infection}

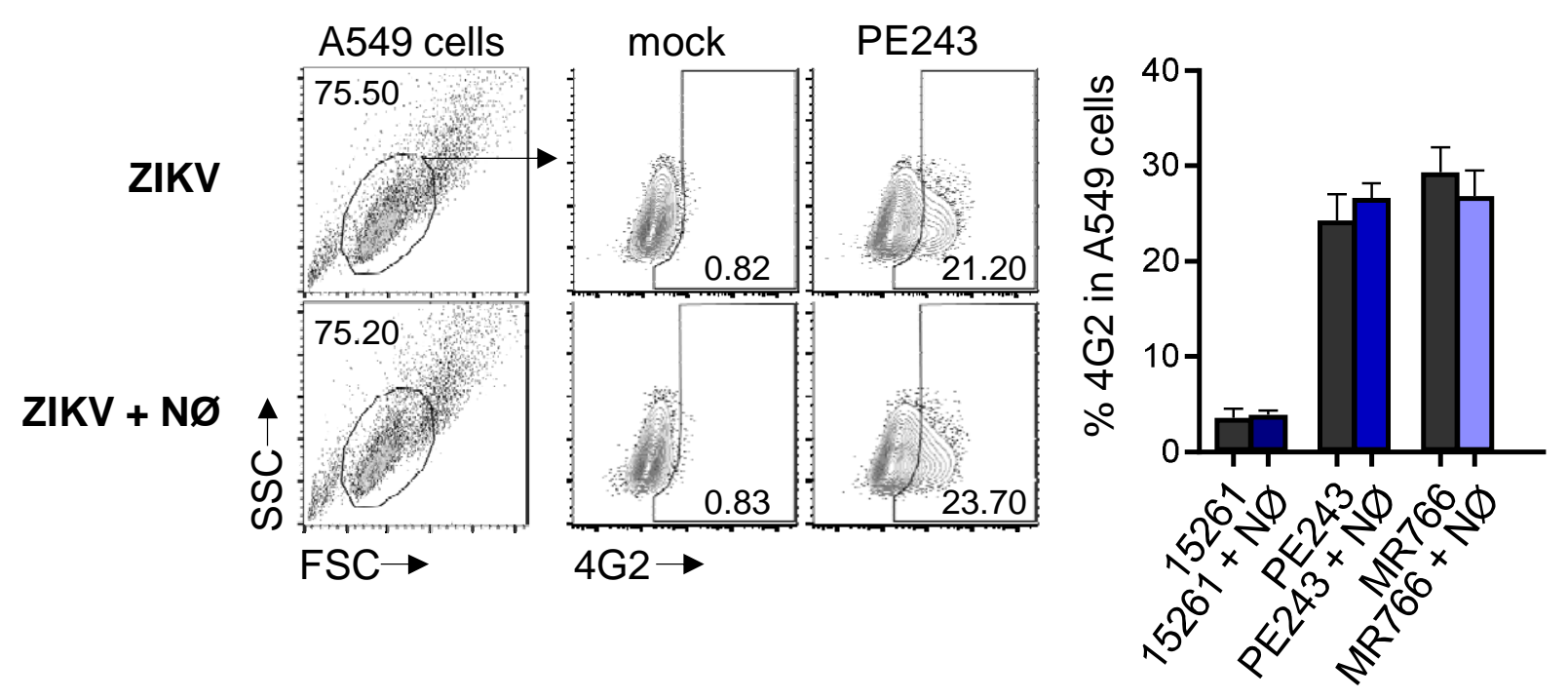


bioRxiv preprint doi: https://doi.org/10.1101/2021.09.26.461875; this version posted September 27, 2021. The copyright holder for this preprint (which was not certified by peer review) is the author/funder, who has granted bioRxiv a license to display the preprint in perpetuity. It is made

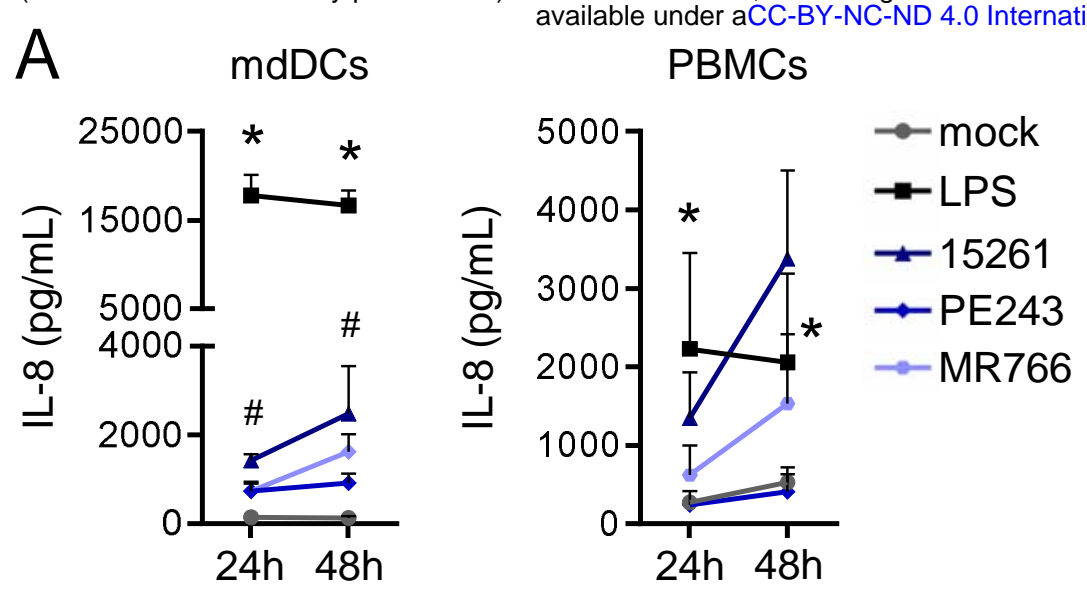

time after stimulation

B

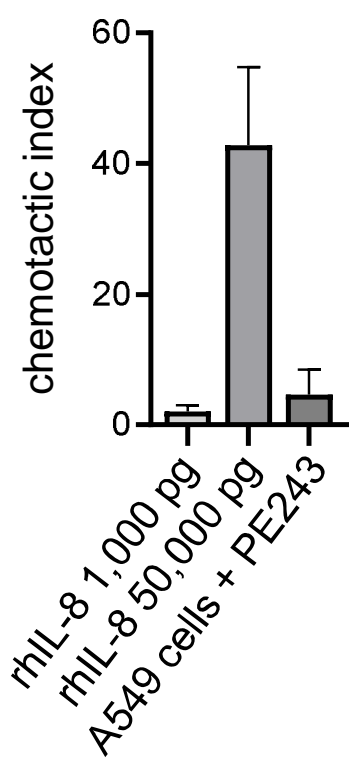


bioRxiv preprint doi: https://doi.org/10.1101/2021.09.26.461875; this version posted September 27, 2021. The copyright holder for this preprint (which was not certified by peer review) is the author/funder, whol has granted bioRxiv a license to display the preprint in perpetuity. It is made

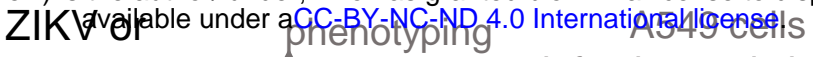
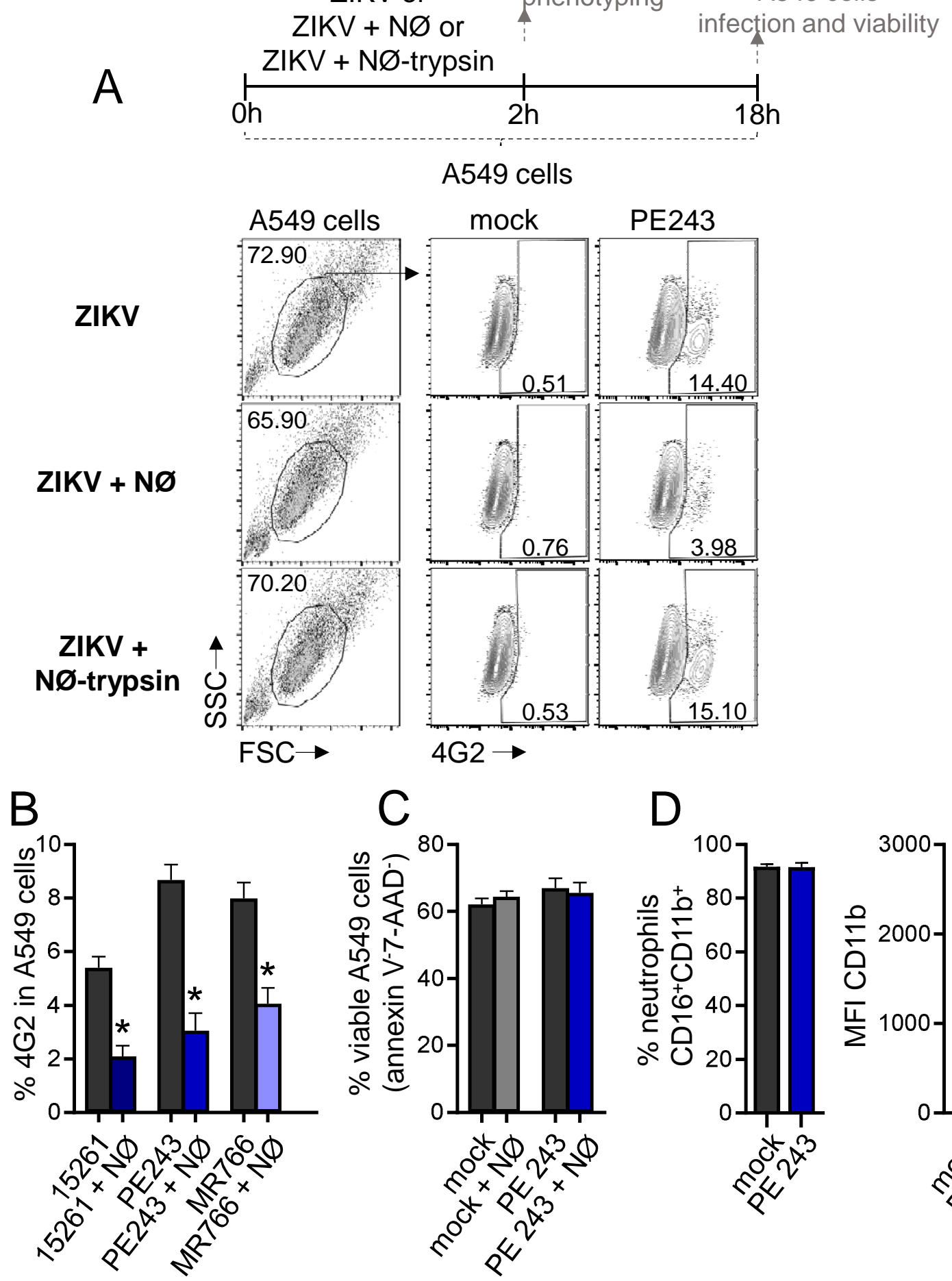

D
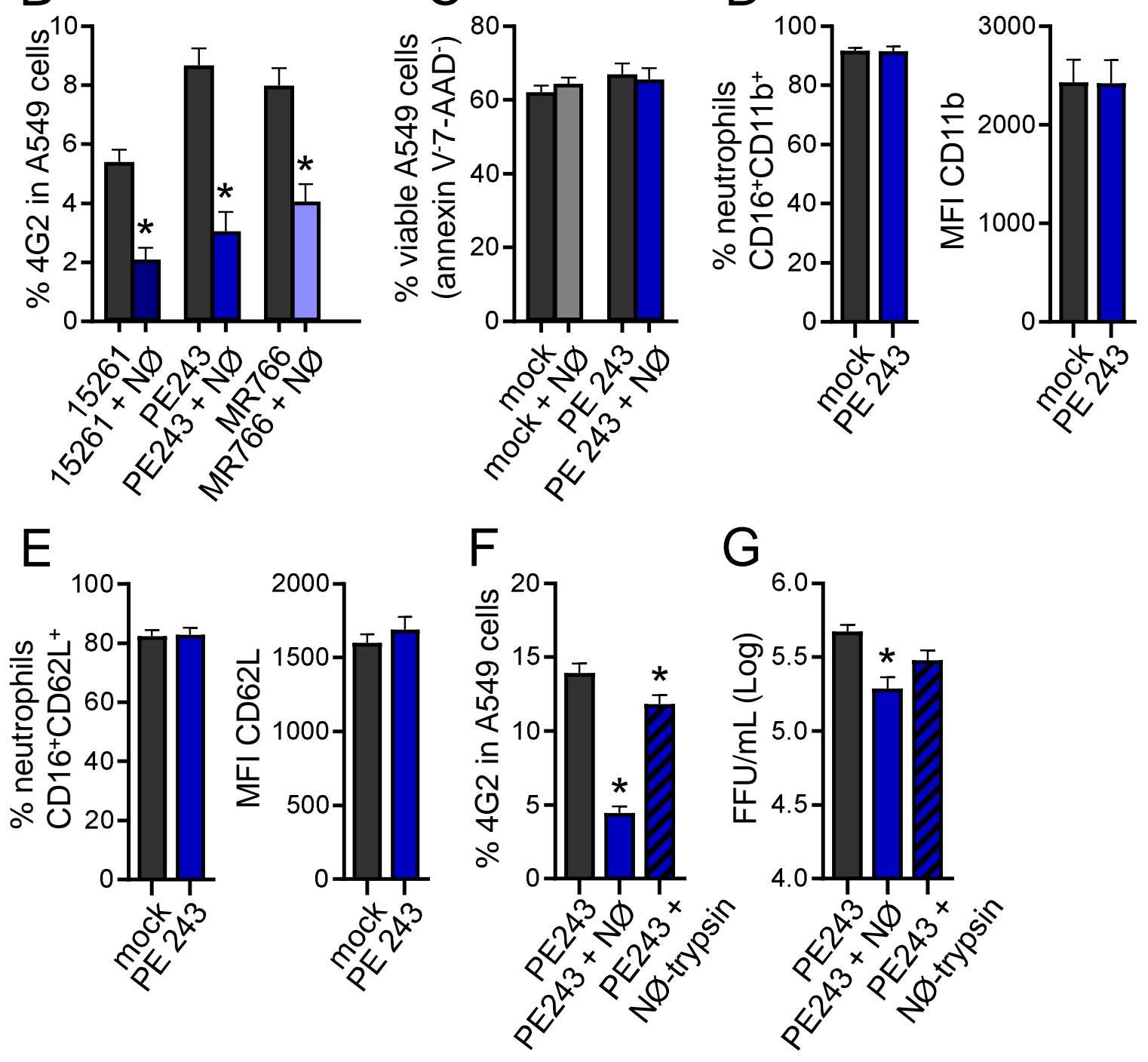
bioRxiv preprint doi: https://doi.org/10.1101/2021.09.26.461875; this version posted September 27, 2021. The copyright holder for this preprint (yhich was not certified by peer review) is the author/funder, who has granted bioRxiv a license to display the preprint in perpetuity. It is made

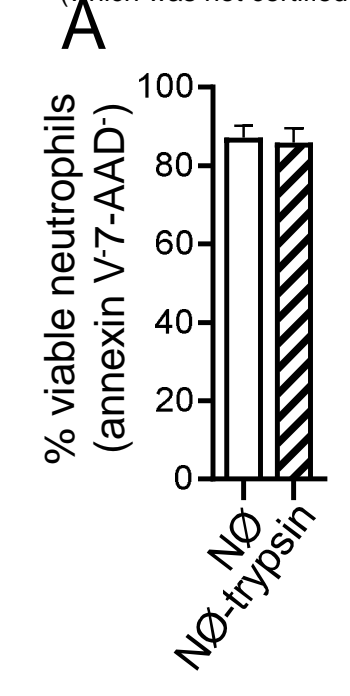

B available under aCC-BY-NC-ND 4.0 International license.
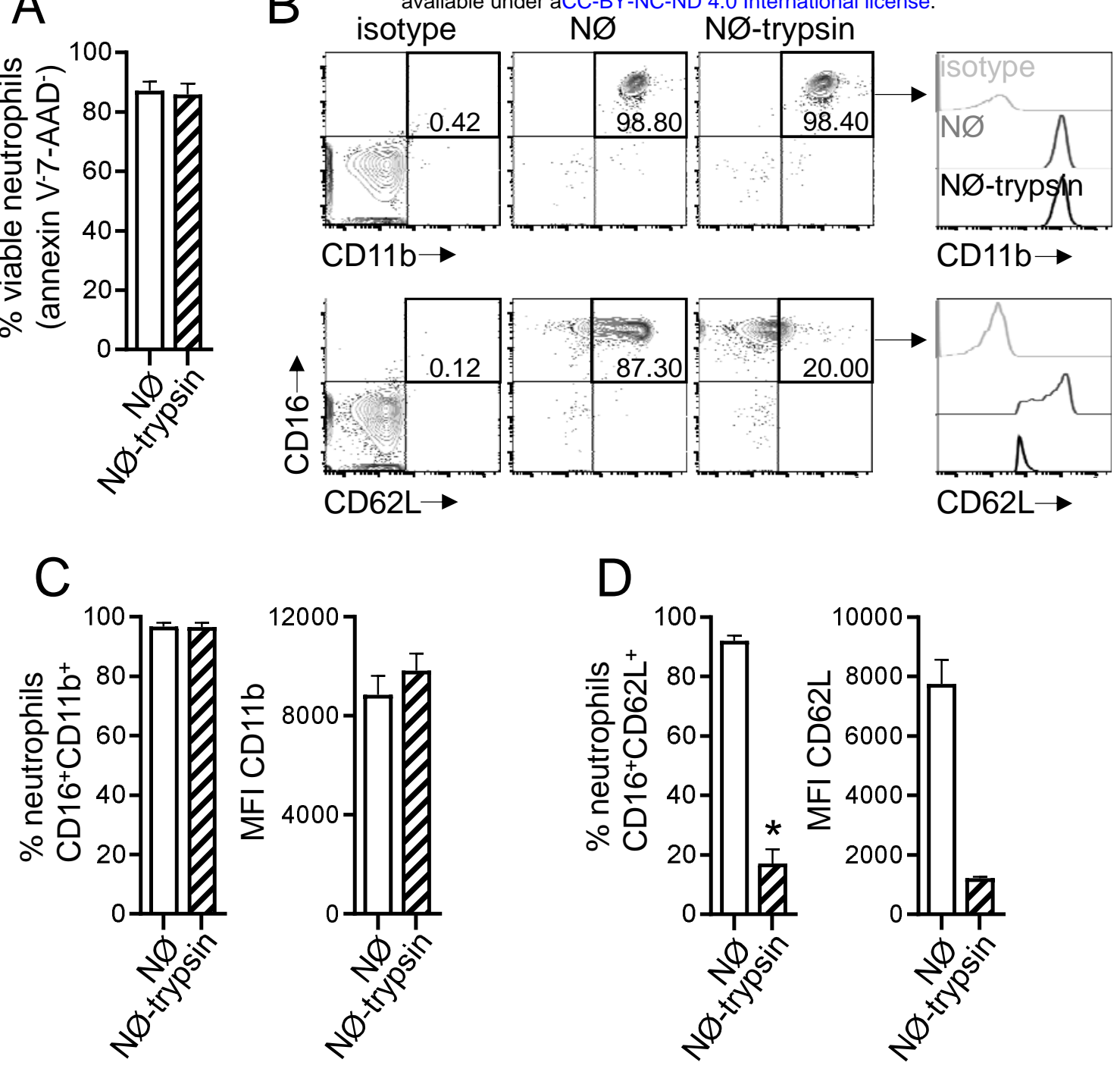
bioRxiv preprint doi: https://doi.org/10.1101/2021.09.26.461875; this version posted September 27, 2021. The copyright holder for this preprint

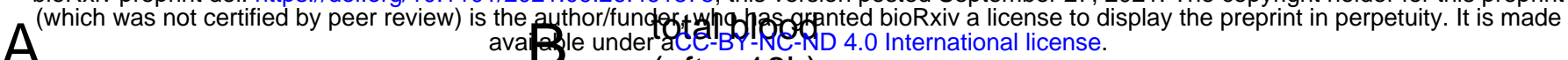
A

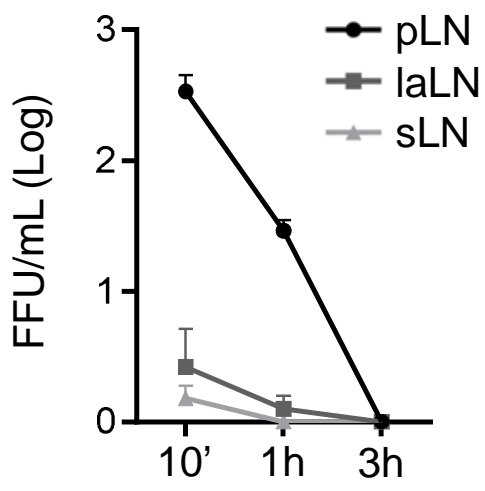

time after ZIKV injection

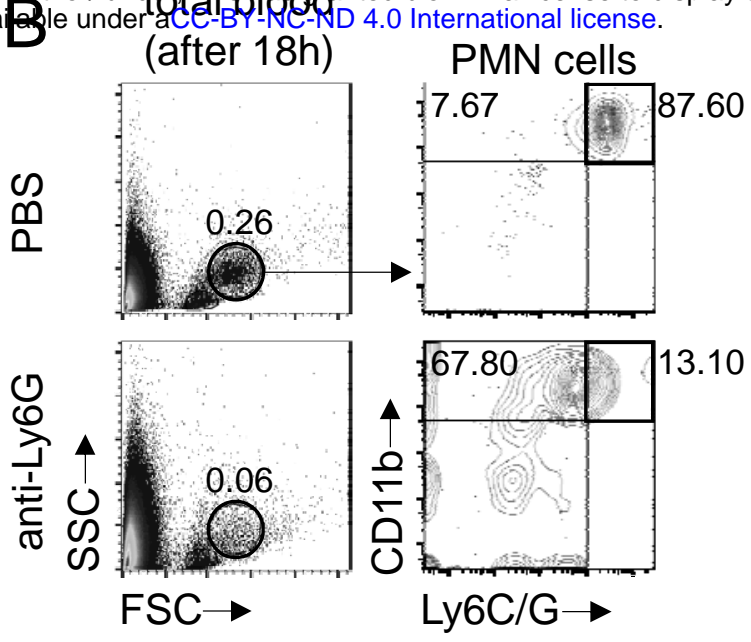

C

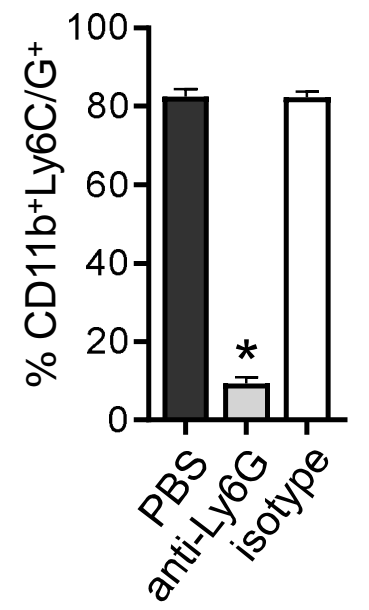

D

anti-Ly6G

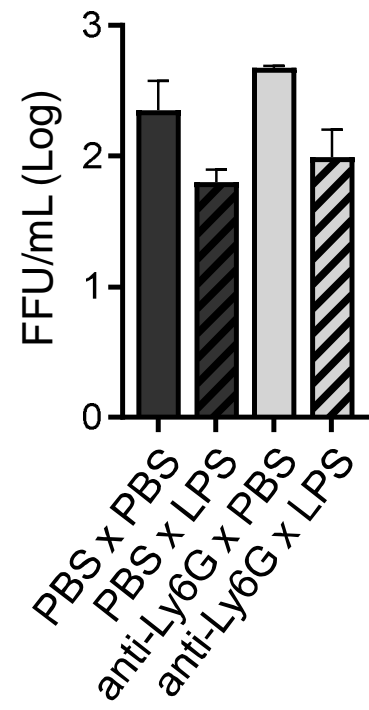


bioRxiv preprint doi: https://doi.org/10.1101/2021.09.26.461875; this version posted September 27, 2021. The copyright holder for this preprint (which was not certified by peer review) is the author/funder, who has granted bioRxiv a license to display the preprint in perpetuity. It is made A

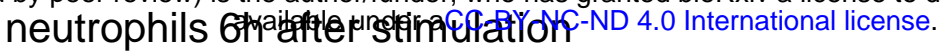
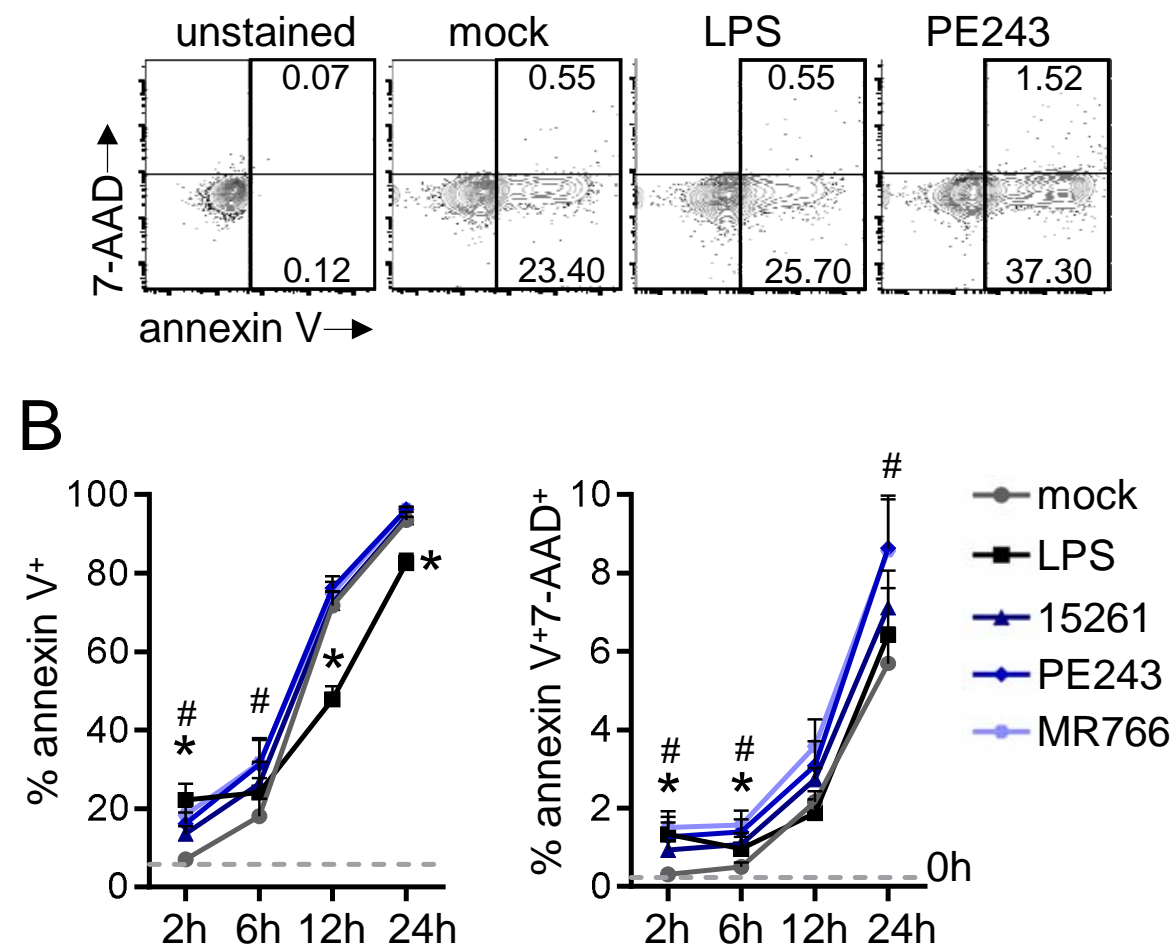
bioRxiv preprint doi: https://doi.org/10.1101/2021.09.26.461875; this version posted September 27, 2021. The copyright holder for this preprint (which was not certified by peer review) is the author/funder, who has granted bioRxiv a license to display the preprint in perpetuity. It is made OIKV

A549 cells

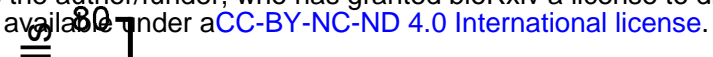

$\overline{\overline{0}}$

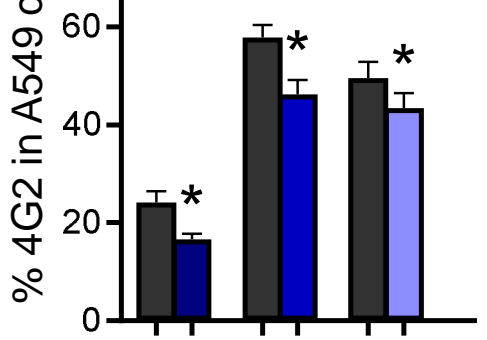

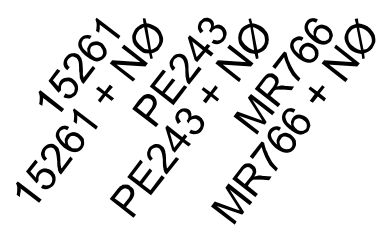

